The Real Exchange Rate, Foreign Aid and Macroeconomic Transmission Mechanisms in Tanzania and Ghana

Juselius, Katarina; Reshid, Abdulaziz Abrar; Tarp, Finn

Published in:

Journal of Development Studies

DOI:

10.1080/00220388.2017.1305106

Publication date:

2017

Document version

Publisher's PDF, also known as Version of record

Document license:

CC BY-NC-ND

Citation for published version (APA):

Juselius, K., Reshid, A. A., \& Tarp, F. (2017). The Real Exchange Rate, Foreign Aid and Macroeconomic Transmission Mechanisms in Tanzania and Ghana. Journal of Development Studies, 53(7), $1075-1103$. https://doi.org/10.1080/00220388.2017.1305106 


\section{The Real Exchange Rate, Foreign Aid and Macroeconomic Transmission Mechanisms in Tanzania and Ghana}

\section{Katarina Juselius, Abdulaziz Reshid \& Finn Tarp}

To cite this article: Katarina Juselius, Abdulaziz Reshid \& Finn Tarp (2017) The Real Exchange Rate, Foreign Aid and Macroeconomic Transmission Mechanisms in Tanzania and Ghana, The Journal of Development Studies, 53:7, 1075-1103, DOI: 10.1080/00220388.2017.1305106

To link to this article: https://doi.org/10.1080/00220388.2017.1305106

ఠ

(C) 2017 UNU-WIDER. Published by Informa

UK Limited, trading as Taylor \& Francis Group.

曲 Published online: 03 Apr 2017.

Submit your article to this journal $\widetilde{ }$

Џll Article views: 816

Q View related articles $\longleftarrow$

View Crossmark data \lceil 


\title{
The Real Exchange Rate, Foreign Aid and Macroeconomic Transmission Mechanisms in Tanzania and Ghana
}

\author{
KATARINA JUSELIUS*, ABDULAZIZ RESHID** \& FINN TARP*,† \\ *Department of Economics, University of Copenhagen, Copenhagen, Denmark, **Department of Economics and Statistics, \\ Linnaeus University, Vaxjö, Sweden, ${ }^{\dagger}$ United Nations University World Institute for Development Economics Research (UNU- \\ WIDER), Helsinki, Finland
}

ABSTRACT A recent study of 36 sub-Saharan African countries found a positive impact of aid in the majority of these countries. However, for Tanzania and Ghana, two major aid recipients, aid did not seem to have been equally beneficial. This study singles out these two countries for a more detailed empirical investigation. The focus is on the effect of aid when allowing external and nominal factors to play a role in the macroeconomic transmission mechanism. We conclude that when monetary and external factors are properly accounted for, then aid has been pivotal to growth in both real GDP and investment.

\section{Introduction}

Recent studies of the impact of foreign aid on economic development tend to find a positive impact of aid on growth. This reflects both better and longer data and more careful methodological choices, and includes work based on the application of modern time-series techniques. Such work was not feasible just a few years ago due to the inadequacy of relevant time-series information in individual aid recipient countries. Juselius, Møller, and Tarp (2014) (henceforth JMT14) is such a study. It provides a comprehensive overview of the long-run impact of foreign aid on a set of key macrovariables (GDP, investment, government expenditure, and private consumption, all in real terms) in 36 sub-Saharan countries from the 1960 s to 2007.

JMT14 relies on a cointegrated VAR (CVAR) approach which finds that in the majority of countries (32) aid has clear and positive effects on either GDP or investment, or both. The cases where aid appears to have had no or even negative effects amount to a very small minority of outlying countries. However, Ghana and Tanzania, two major aid recipients, appear to belong to the latter. Over the years, the two countries have influenced much of the literature and debate about economic development in Africa, including the role of foreign aid. Therefore, Ghana and Tanzania merit further study. The overall scope of the present analysis is exactly this, that is to start from JMT14, dig deeper and try to uncover whether the JMT14 findings as regards Ghana and Tanzania hold up when some of the assumptions underlying JMT14 are subjected to careful scrutiny.

The broad selection of variables in JMT14 restricted the analysis to closed economy effects. Accordingly, their results reflect a ceteris paribus assumption, where 'open economy' influences are kept constant. In addition, only real variables were included in the JMT14 empirical model, which

Correspondence Address: Finn Tarp, UNU-WIDER, Katajanokanlaituri 6 B, FI-00160 Helsinki, Finland. Email: tarp@wider.unu.edu

(C) 2017 UNU-WIDER. Published by Informa UK Limited, trading as Taylor \& Francis Group.

This is an Open Access article distributed under the terms of the Creative Commons Attribution-NonCommercial-NoDerivatives License (http://creativecommons.org/licenses/by-nc-nd/4.0/), which permits non-commercial re-use, distribution, and reproduction in any medium, provided the original work is properly cited, and is not altered, transformed, or built upon in any way. 
implies that nominal and real variables were treated as dichotomous. We wish to go further here and also note that, in effect, the ceteris paribus assumption in JMT14 comprises a very large number of variables and factors, such as country-specific characteristics. Some of these are likely to have had significant impact on the economy. It is, for example, well established that structural reforms, other policy interventions, conflicts, droughts and floods, may result in very large changes in the macrovariables under study and, therefore, can be highly influential for the estimated results (Nielsen, 2008). Unless adequately controlled for, they will tend to bias the model parameter estimates.

JMT14 did model extraordinary events such as those mentioned, using step dummies to account for equilibrium mean shifts in the long-run relations, on the one hand, and impulse dummies to account for extraordinary shocks in the equations, on the other. While this was a safeguard that major events were controlled for, the large number (36) of countries involved prevented a more detailed analysis of all possible events. The present study is intended to fill this gap in two important countries, paying particular attention to better understanding the long- and short-run effects of major political and economic events on economic development. These include major structural reforms that have played a key role in both countries.

Finally, while JMT14 focused on uncovering the causal links between aid and the macrovariables and on the long-run impact of a 'shock' to aid (measurable with some simple test statistics and therefore comparable over countries), the JMT14 study did not address the dynamics of the transmission mechanism of aid. This is an econometrically much more complex and demanding challenge, which is better pursued in a two-country comparative case context.

In sum, JMT14 provided an overview based on a number of simplifying assumptions. They were used because of the nature of the very large and comprehensive sample of countries and variables, not because the assumptions were inherently plausible per se. In addition, a series of events were controlled for in a stylised manner. It is on this background of interest to establish whether two major African aid recipients, Ghana and Tanzania, turned out as outliers due to omitted variable effects or whether these two countries are in some sense special. In the latter case, we would like to understand why. More specifically, the aim of this study is to respond to three key concrete questions:

(1) What was the effect of major structural reforms on the macroeconomic growth rates in Ghana and Tanzania? Do the effects differ, and if so why?

(2) Does the inclusion of the real exchange rates (open economy effects) and the inflation rate (nominal effects) significantly alter conclusions regarding the long-run impact of aid on key macroeconomic variables in Tanzania and Ghana?

(3) Are the macroeconomic transmission mechanisms in Ghana and Tanzania similar (and if so to which extent) or are they different; and what is the potential role played by Dutch disease?

The structure of the study is as follows: Section 2 gives a historical overview of the main political and economic events in Tanzania and Ghana. Section 3 is a comparative discussion of their respective growth paths and how these paths have been affected by structural reforms. Section 4 introduces the cointegrated VAR model and its country-specific specification and discusses at some length how to control for major structural reforms. Section 5 determines the cointegration rank in the two models while Section 6 attempts to answer question 2 above by discussing the two estimated common stochastic trends and their loadings as well as the estimated final impact of shocks onto the system. Section 7 attempts to answer question 3. It first introduces eight rules for how to interpret an identified structure of irreducible cointegration relations and then discusses the two estimated longrun structures relying on these rules. Section 8 concludes.

\section{Historical overview}

Given our focus on the role of foreign aid, the real exchange rate and inflation for the determination of real GDP, investment and consumption in Tanzania and Ghana, we provide 


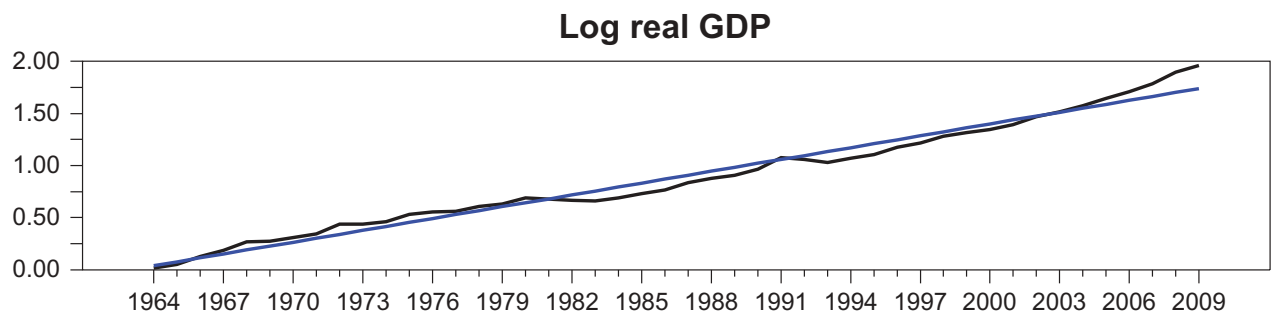

Log real investment

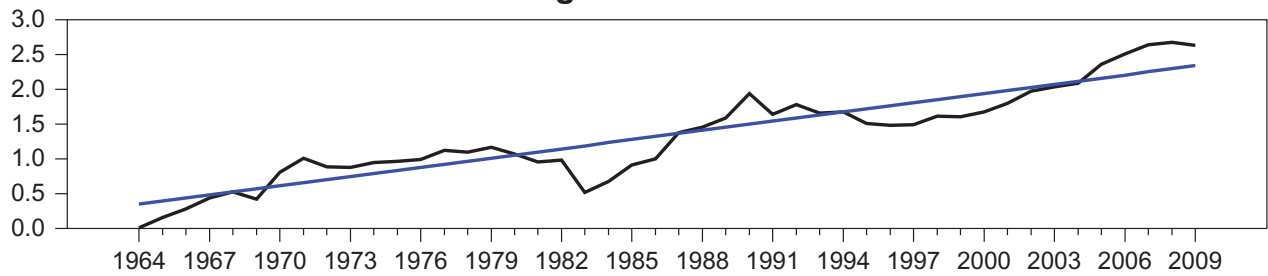

Log real private consumption

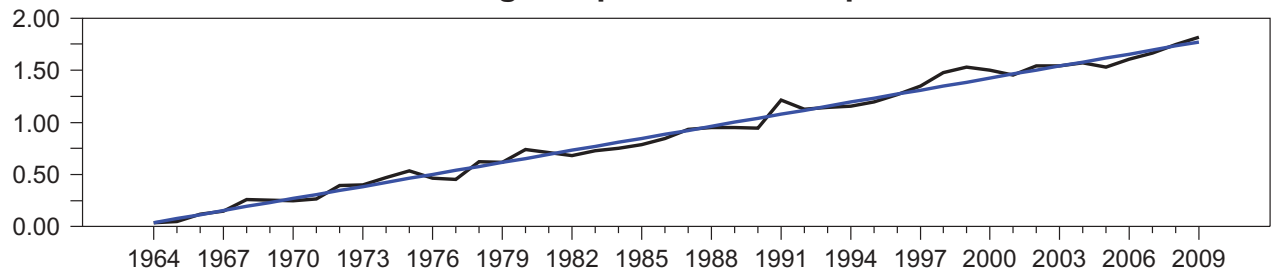

Log real government expenditure

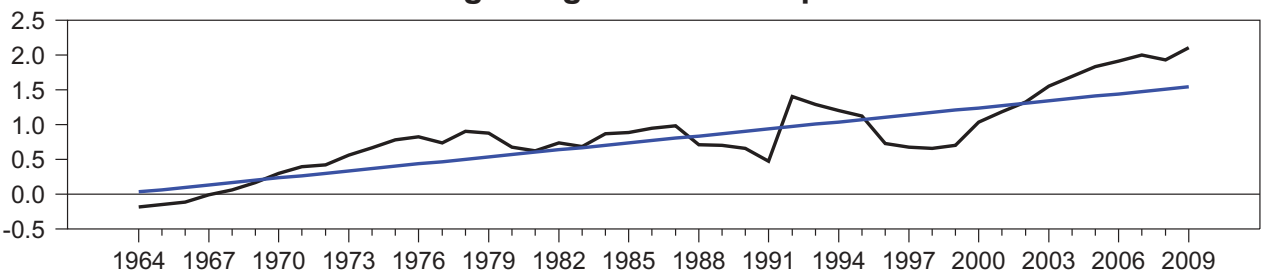

Figure 1. The time path of Tanzanian (a) log real GDP, (b) log real investment, (c) log real private consumption and (d) log real government expenditure.

Notes: The log scale can be translated to relative changes over the period as follows: real GDP increased 5.7 times, real investment 8.2 , real private consumption 4.5 times, and real government expenditure 7.3 times.

in Figures 1-4 an overview of the historical developments in these series over the period of investigation (1968-2009). Figures 1 and 3 describe GDP, aggregate investment, private consumption and government expenditure (all in real terms), and Figures 2 and 4, show official development assistance (ODA), and the real dollar exchange and inflation rates. All variables are in logarithmic values (see also Table A3 in the Appendix). A first observation is that five variables (GDP, aid, consumption, investment, government expenditure) are distinctly trending, whereas the remaining two variables (inflation, the real exchange rate) do not exhibit linear trends, except very locally.

An overriding thesis here is that persistent deviations from long-run trends are very helpful in understanding the historical dynamics of macroeconomic transmission mechanisms and the role of foreign aid. Such deviations from long-run paths usually indicate imbalances in underlying economic structures and are, arguably, very informative in trying to uncover the impact of adopted economic policy and other changes. For this reason, we study both long-run trends in the data on the one hand, and deviations from these trends on the other. The CVAR model, to be introduced in the next section, is tailor-made to study such features of the data. 
Log aid

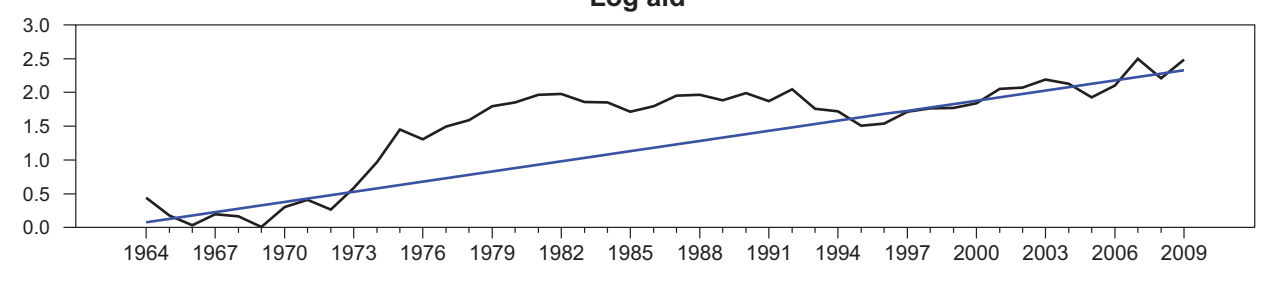

Log real exchange rate
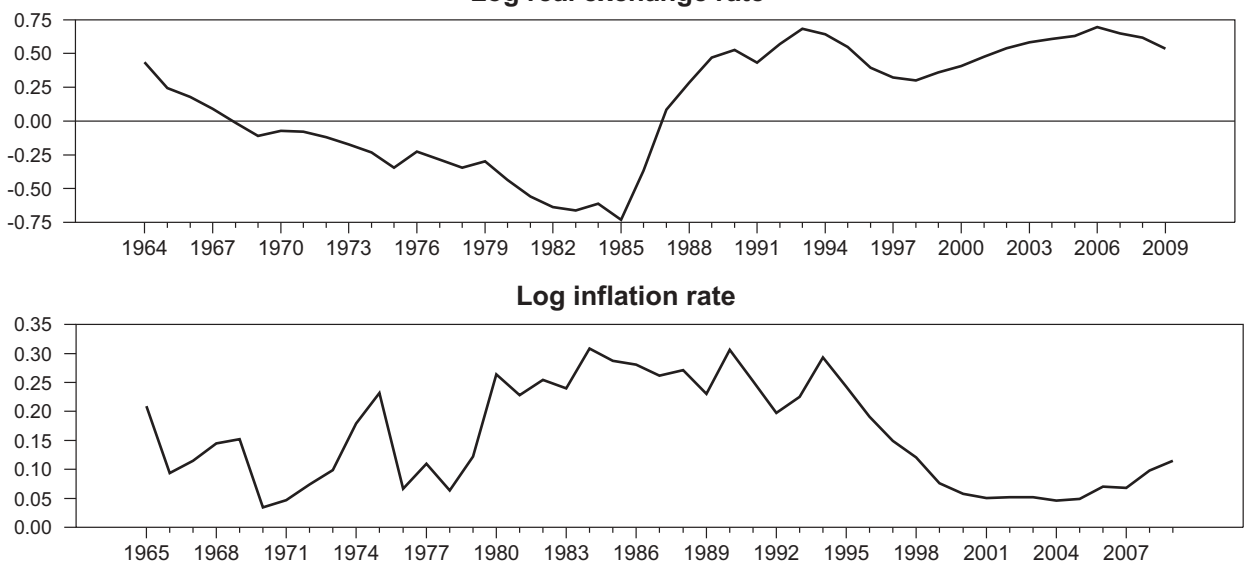

Figure 2. The time path of Tanzanian (a) log aid, (b) log real exchange rate, and (c) log inflation rate. Notes: The log scale can be translated to relative changes over the period as follows: aid grew 10 times, the real exchange rate devalued around 4.3 times its value in 1985, and inflation was roughly 35 per cent at its highest.

\subsection{Tanzania}

Tanzania became independent in 1961 and the first period after the transition from colonial rule differs markedly from subsequent periods. The years 1961-1967 are therefore unlikely to be informative in our analysis and have been omitted. Accordingly, we begin in 1967 where Nyerere took over as President. The Tanzanian government also endorsed the 1967 Arusha Declaration, marking a shift towards a centrally-controlled socialist model of development emphasising self-reliance, nationalisation of key economic sectors, villagisation of production (known as Ujamaa) and public provision of health and education (Rotarou \& Ueta, 2009). In 1973 a National Price Commission was established to facilitate price control; a managed exchange rate system was introduced; rural marketing co-operatives were abolished and replaced by a monopoly marketing board; over seven million people were resettled forcefully under the Ujamaa villagisation programme; and the Basic Industrialisation Strategy (BIS) introduced state-led investment programmes which were largely financed by foreign aid (Bigsten \& Danielsson, 1999; Potts, 2005). As public expenditure increased, the government became increasingly dependent on donor support, and foreign aid financed nearly half of Tanzania's import bill in this period (Van Arkadie, 1995). During 1973-1975, net ODA more than doubled from USD 441 to 1044 million annually according to OECD/DAC.

Figure 1(a) shows that real GDP grew along a stable path until the end of the 1970s, but behind the seemingly stable growth rates there were signs of mounting structural problems. Policies undertaken after 1973 had increased the role of the state beyond its administrative capacity leading to inefficiency and under-utilisation of resources (Potts, 2005). High mark-ups in government marketing monopolies and a strongly overvalued exchange rate reduced the returns from exports, and state-led government investment programmes and import substitution strategies increased the structural dependency on imported inputs and foreign aid (Van Arkadie, 1995). A temporary coffee boom and substantial donor support helped postpone the crisis (Bigsten \& Danielsson, 1999). The ensuing crisis at the end of the 


\section{Log real GDP}

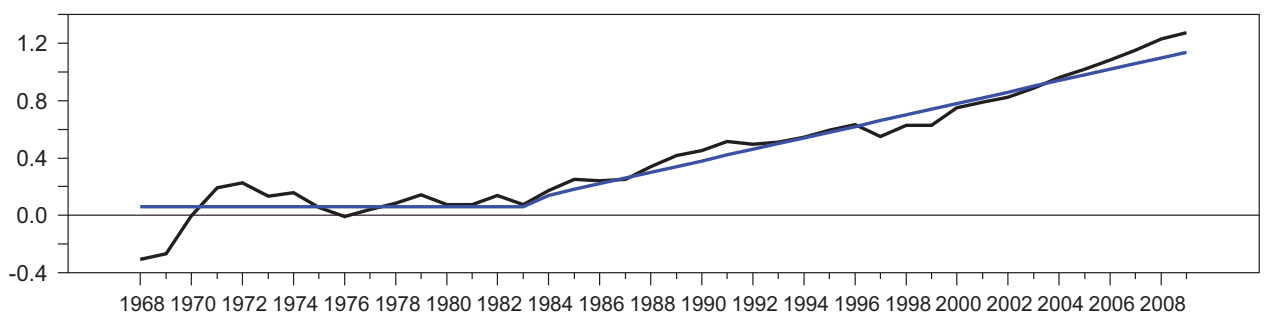

Log real investment

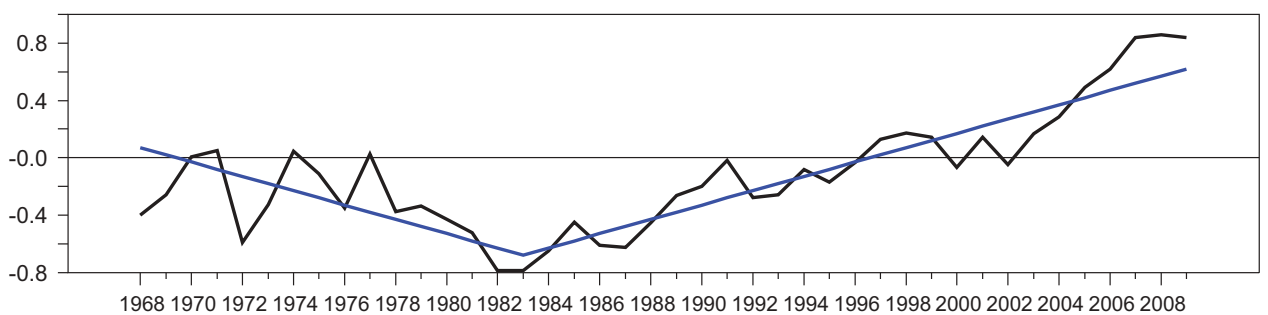

Log real private consumption

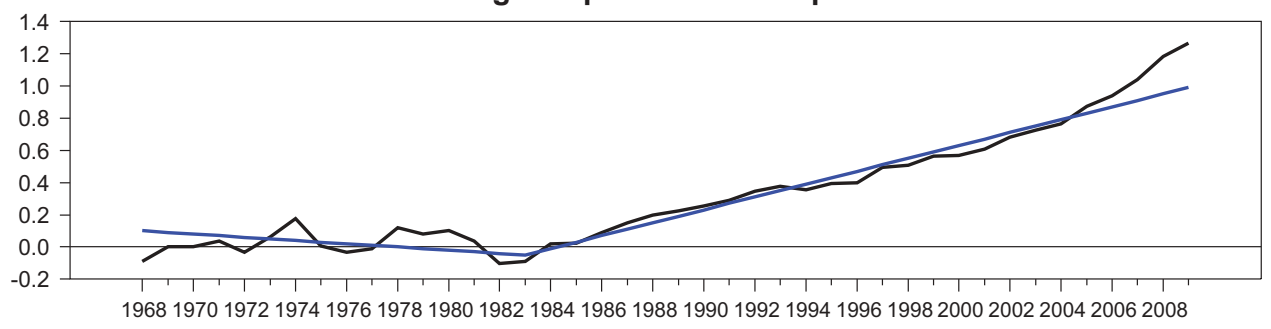

Log real government expenditure

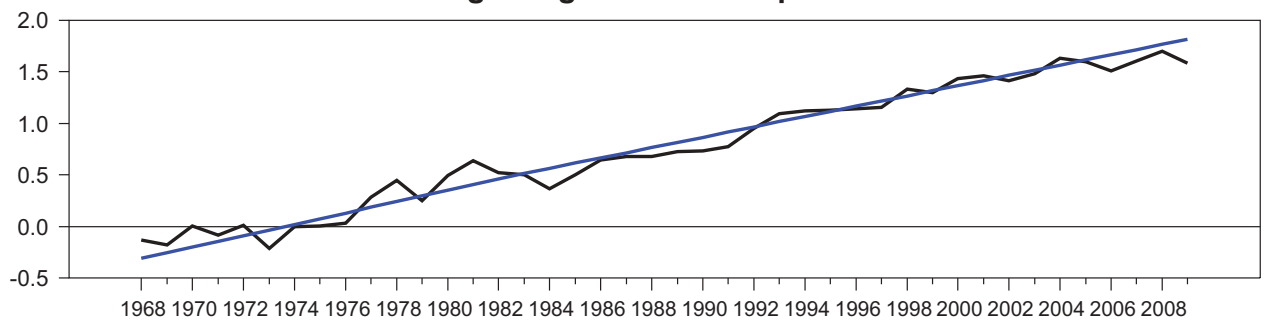

Figure 3. The time path of Ghanaian (a) $\log$ real GDP, (b) log real investment, (c) log real private consumption and (d) $\log$ real government expenditure.

Notes: The log scale can be translated to relative changes over the sample period as follows: real GDP increased 3.5 times, real investment 2.7 times, real private consumption 3.5 times, and real government expenditure 4.5 times.

1970s was aggravated by external factors such as the 1979 oil price rise, the Uganda conflict (19781979) and a serious drought (1981-1982).

Foreign aid was exceptionally high from 1972 to 1981, more than twice its long-run trend value. Thereafter aid inflows started declining (Figure 2(a)). The original generosity of donor countries was to a large extent associated with President Nyerere, a well educated and charismatic leader. In particular, the Nordic countries were prepared to give Nyerere's socialist experiment a realistic chance. Nevertheless, because of mounting structural problems in the economy, IMF and the donors increased their pressure for more drastic liberalisation measures in the early 1980s. As the government initially refused to cooperate on these reforms, aid flows started declining. As a result, Tanzania experienced a 


\section{Log aid}

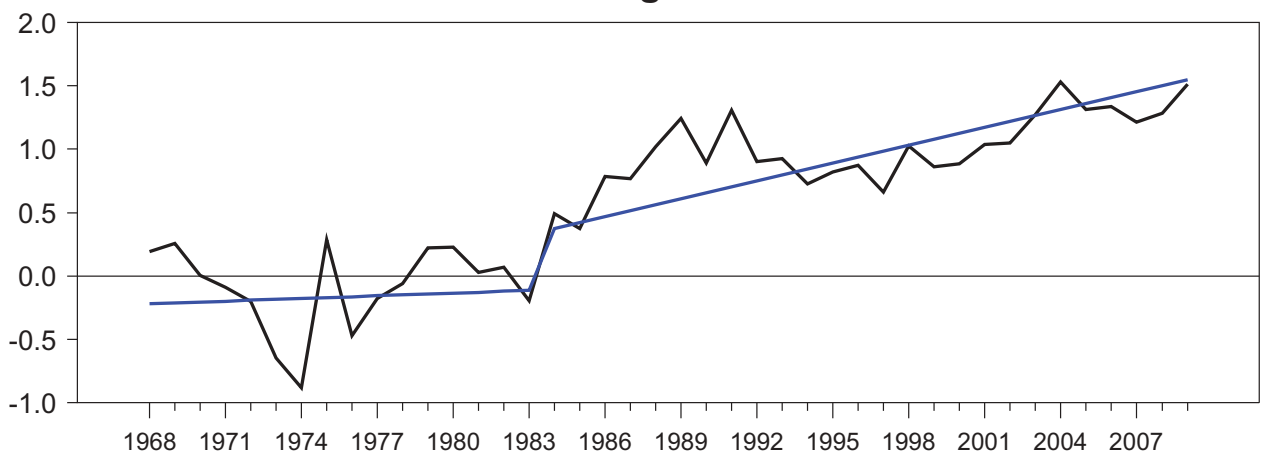

Log real exchange rate

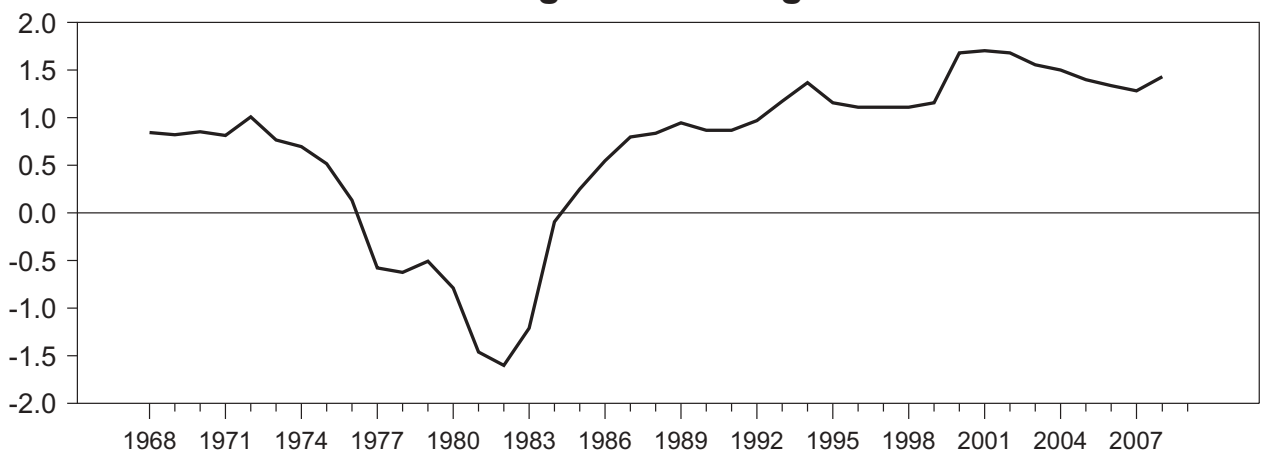

Log inflation rate

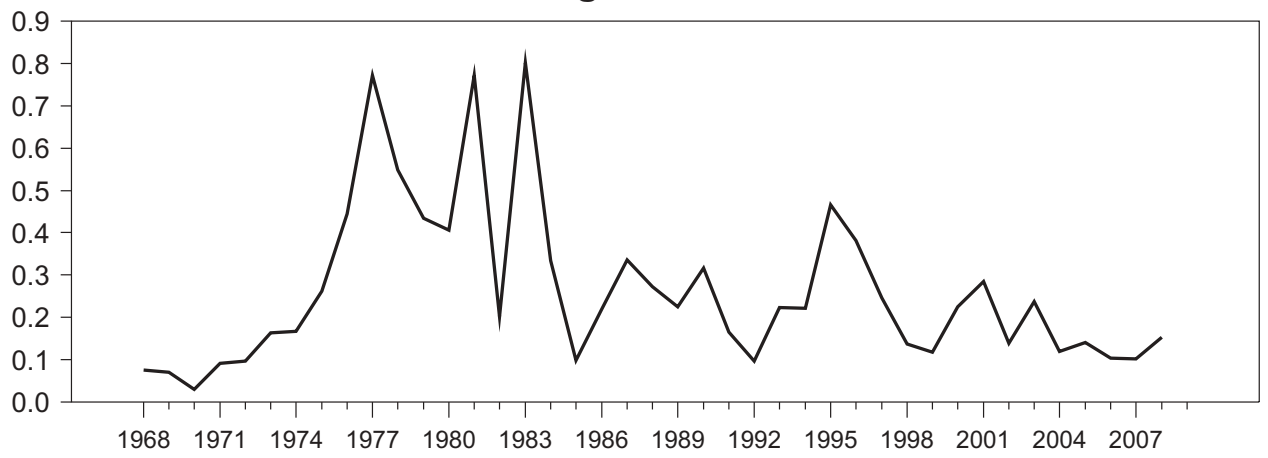

Figure 4. The time path of Ghanaian (a) log aid, (b) log real exchange rate, and (c) log inflation rate. Notes: The log scale can be translated to relative changes over the period as follows: aid grew 4.5 times, the real exchange rate devalued around 14 times its value in 1982, and inflation was roughly 120 per cent at its highest.

shortage of imported inputs and a declining GDP. Yet in spite of tensions between donors and the government, aid remained above its long-run trend until the mid-1990s.

The large inflows of aid during the Nyerere era did not result in proportional growth in income. Figure 1(a) shows that GDP closely followed its long-run growth path although foreign aid doubled. An important reason why real GDP did not grow more can be related to the strong growth of Tanzanian prices without a compensating devaluation of the Tanzanian shilling. As Figure 2(b) shows, the real exchange was subject to an ongoing appreciation during the Nyerere period. That the Tanzanian shilling was seriously overvalued can, for example, be inferred from the black market rate which shows that the US dollar was traded at prices dramatically above the official rate. For 
Nyerere, maintaining a strong currency was a sign of prestige (and as a way to avoid imported inflation), and he refused to devalue the shilling in spite of strong pressure by the IMF, the donor countries and internal analysts. No doubt, the strong real appreciation of the shilling tended to offset the benefits of the generous aid.

By the end of the 1970s, the early promising years were definitely over. Investment declined dramatically as a result of lost competitiveness due to the overvalued shilling and declining aid (Figure 2(a)). GDP dropped below its long-term growth path (Figure 1(a)) and so did government expenditure (Figure 1(d)) albeit less than by investment and GDP. As monetary expansion was used to compensate for the declining aid, inflation started increasing (Figure 2(c)). By insisting on a strong shilling in a period of structural weaknesses, Nyerere missed a golden opportunity to exploit the generous aid as a means of putting Tanzania on a high-growth path. Instead, Tanzania entered into a prolonged structural adjustment period with GDP growth rates below those of the 1970 s.

The first Structural Adjustment Programme implemented in 1983-1985 reflected a home-owned effort to liberalise the economy. It included measures such as (i) import liberalisation through an 'own fund' import scheme, (ii) depreciation of the Tanzanian shilling, (iii) freezing the budget deficit at the previous level, and (iv) liberalisation of trade with domestic food products (Van Arkadie, 1995; Wobst, 2001). Although the programme resulted in a (modest) reversal of the negative trends in real output growth and domestic investment, high inflation and the deteriorating balance of payments continued. Also the parallel market economy increased in scope. Yet, the home-owned reform measures signalled a major shift towards economic liberalisation.

After Ali Hassan Mwinyi took over the presidency from Nyerere in 1985, negotiations with the IMF resumed. President Mwinyi agreed to implement significant stabilisation and structural adjustment policies under the Economic Recovery Programmes (1986-1993) (Agrawal, Ahmed, Mered, \& Nord, 1993). While economic growth recovered to some extent, per capita growth remained modest and even negative in some years. Not until 1996 was the turmoil of the Nyerere period followed by more sustainable growth (Figure 1(a)).

After the devaluation of the shilling in 1985, the gap between the parallel and the official market rates narrowed from its peak of 800 per cent in 1985 to only 30 per cent in early 1992 (Bigsten \& Danielsson, 1999). The National Investment Promotion and Protection Act of 1990, which provided incentives and guarantees to foreign investors (in particular for gold and petroleum exploration) and two legal acts in 1991 and 1992, which allowed free entry and exit for foreign banks, made foreign investment more attractive, especially in gold mining (Cooksey \& Kelsall, 2011). Furthermore, the high inflation rates of the 1980s declined to single digits after 1996 (Figure 2(d)).

In 1995 Benjamin Mkapa became president, and the government intensified the liberalisation process. An agreement was signed with the IMF on an Enhanced Structural Adjustment Facility for the period 1998/1999 to 2000/2001, and the liberalisation of trade and finance intensified. The exchange rate was allowed to adjust within a crawling band and various reforms affecting the civil service and tax collection were undertaken. These reforms were accompanied by increasing aid. Since then economic performance has been strong, the relationship with donors usually good, and Tanzania has continued to be one of the major recipients of foreign aid. ${ }^{1}$

It is fairly remarkable that over this turbulent period private consumption did not show much variation around its long-run path (Figure 2(c)). A possible explanation (in addition to data collection challenges) is that the majority of the population continued to live at or close to subsistence levels without much scope for either increases or decreases in consumption patterns.

\subsection{Ghana}

Political and economic developments in post-Independence Ghana (see Aryeetey, Harrigan, \& Nisanke, 2000; Aryeetey \& Kanbur, 2008) have been quite different from those of Tanzania, albeit with some similarities. The graphs of the seven time series in Figures 3 and 4 illustrate this. A prominent feature is that among the variables included only government expenditure exhibited long- 
term growth over the full sample period (Figure 3(d)). Real GDP, investment and consumption exhibited growth only after the introduction of structural reforms in 1983 (Figure 3(a)-(c)).

The pre-reform period was politically unstable with frequent military coups and counter coups contributing to gross economic mismanagement and a deteriorating investment climate. The economy was 'muddling through' with inefficient state-owned enterprises operating with excess capacity. The consequence was low productivity, an over-valued currency, high inflation rates, large public deficits, and high interest rates (Aryeetey \& Tarp, 2000; Leechor, 1994). In most of the pre-1983 period, economic policy focused on import substitution, exchange rate and price controls with the State strongly present in most macroeconomic activities (Aryeetey, Fosu, \& Bawumia, 2002).

Foreign aid dropped quite significantly in the early 1970s (Figure 4(a)) when President Acheampong (who was later to be executed in 1979) announced that Ghana repudiated its international debts. Thus, in contrast to Nyerere's Tanzania, Ghana was very far from being a donor darling. But similar to Tanzania, the Ghanaian cedi was allowed to appreciate very strongly during the 1970s and until 1983 (Figure 4(b)). The long period of persistent real appreciation combined with very high inflation rates had a disastrous effect on real investments which exhibited a declining trend until 1983 (Figure 3(b)). Also private consumption stagnated, and even declined in some years in stark contrast to government expenditures. Annual inflation rates soared reaching more than 100 per cent (Figure 4(c)) as a result of government deficit financing by excessive expansion of the money supply. Also exogenous factors such as the 1983 drought and the return of millions of Ghanaian workers from Nigeria contributed to the severe economic crisis at the beginning of the 1980s (Fosu \& Aryeetey, 2008).

Because of deteriorating terms of trade Ghana was literally forced to change its economic policies and turned to the IMF and the World Bank for assistance in 1983. The result was the IMF Economic Recovery Programme (1983-1985) focusing on stabilisation and liberalisation of various sectors of the economy by exchange rate adjustments (increasing the US dollar price by $250 \%$ in 1983), stringent fiscal and monetary policies, trade liberalisation, civil service and public sector reforms, and privatisation of government owned enterprises.

The programme had impact. The annual rate of inflation declined from more than 100 per cent in the pre-reform period to about 25 per cent in the late 1980s and first half of 1990s after which it finally came down to the present low levels. Foreign aid increased substantially (Figure 4(a)), easing external financial constraints and promoting a higher economic growth path, and possibly also the relatively high inflation rates during the first reform period, as the aid was mostly spent on the domestic economy (Leechor, 1994).

The economic reforms combined with increasing aid resulted in a strong recovery. The pre-reform period with no real growth was replaced with steady growth in all macro-variables. This success became identified with the long-serving Finance Minister, Dr. Kwesi Botchwey. With his departure in the early 1990s, the earlier cohesiveness in the Ghanaian reforms seemed to be temporarily affected. The reform process slowed down, and with the introduction of multiparty democracy in the early1990s, Ghana experienced her first political-economic business cycle. In 1995 the government attempted to introduce a value-added tax reform without sufficiently involving the Ghanaian people. The resulting civil disturbances forced the government to withdraw the tax which, after a broader information campaign, was reintroduced three years later, now at 10 per cent rather than the originally proposed 15 per cent (see Tsikata, 2001). However, since 1996 macroeconomic conditions have overall been relatively stable and real GDP has steadily grown at rates faster than in most other sub-Saharan African countries. In parallel, Ghana has become one of Africa's success-growth stories.

\section{Growth and structural reforms in Tanzania and Ghana compared}

Both Tanzania and Ghana experienced a long period of real appreciation of their currencies in the 1970s, and both initiated economic reforms in the beginning of the 1980 s due to deteriorating economic conditions. A very strong devaluation in the mid-1980s was also a major step to regain 
economic growth in both cases. While there are similarities there are also significant differences between the two cases. ${ }^{2}$ In Tanzania the harmful effects of the continuing real appreciation in the 1970s were alleviated by generous inflows of foreign aid. This was not the case in Ghana, which experienced very modest inflows of foreign aid after the 1972 default on foreign loans. As a consequence, Tanzania experienced average growth of GDP at around 4-5 per cent per annum with a population growth of 2.9 per cent. In contrast, Ghana's economy did not expand at all while population grew at 2.6 per cent per annum. Thus, per capita growth was positive in Tanzania and negative in Ghana.

Both countries experienced significant nominal growth in the pre-reform period. Yet, while annual inflation rates in Tanzania stayed at rather moderate levels of around 15 per cent, they reached very high levels of 50-100 per cent and even more in Ghana. Similarly, the annual real currency appreciation in Tanzania was only 10 per cent thanks to generous aid, whereas in Ghana it averaged 100 per cent. During the first years of the reform period both countries experienced average inflation rates of around 25 per cent implying increasing inflation rates for Tanzania (possibly due to declining aid) and decreasing rates for Ghana (due to increasing aid) compared to the pre-reform period. Since 1998 inflation rates in both countries have come down to 10 per cent or lower.

We also note that over the full sample period the large appreciation rates of the real exchange rates in the 1970s have roughly been compensated by the equally large devaluations since the mid-1980s. Similarly, increases in inflation rates in the first period have been compensated by the subsequent decreases in the second period. Overall, the real exchange rate has depreciated somewhat in both Tanzania and Ghana during the period under study.

Tanzanian real GDP growth in the 1970s was partly driven by state-led industrialisation, mainly financed by foreign aid, and by public investment in projects that improved public welfare such as provision of better hospitals, schools and clean water. All this meant higher employment and a more positive attitude towards the government. The widespread scepticism shared by many people in Tanzania against the economic reforms can partly be explained by the stronger legitimacy of the Nyerere government. It had, after all, provided them with free health care, schooling and relative stability. At the same time, these positive advances had been funded (or made possible) by generous aid flows. So when Tanzania's donors started to withdraw support at the beginning of the 1980s, output started to decline, in part due to a lack of imported inputs, which resulted in further underutilisation of previously created capacity (Bigsten \& Danielsson, 1999). The fact that investment growth was generally higher than GDP growth also suggests that at least some of the investments made did not meet reasonable criteria for economic returns.

In contrast, the population in Ghana suffered significantly under the adverse economic conditions in the pre-reform period where high inflation combined with the strong real appreciation of the currency caused investment to decline and consumption to stagnate. This reinforced the commitment to economic reforms in Ghana. When the reform process started in 1983 the macroeconomic picture changed considerably. Output expanded and grew at an average annual rate of 5 per cent, private consumption at an average rate of 5.6 per cent, whereas investment rebounded at an impressive 9 per cent annual growth rate. Only government expenditure declined somewhat from the previous 6 per cent per annum to approximately 5 per cent. The latter can be related to the strong devaluation of the real exchange rate and the strong conditionalities tied to the foreign aid that began flowing into the country again.

The economic liberalisation reforms no doubt had a positive effect on the macroeconomy in Ghana after 1983 and probably also in Tanzania. However, for both countries the growth rates of investment were higher than those of GDP suggesting that investments may have been characterised by poor quality and low productivity (see Bigsten \& Danielsson, 1999; Husain \& Faruqee, 1994; Leechor, 1994).

Thus, the structural reforms in the mid-1980s changed economic conditions significantly to the better in Ghana, whereas growth rates in Tanzania essentially did not recover their pre-1983 levels until around 1996. Why is this the case? Tsikata (2001) argues that one reason was that the reform programme in Ghana was largely drawn up domestically and that this contributed to a larger degree of domestic ownership than in Tanzania where reforms were seen as being imposed from the outside. The 
slow pace of implementation in Tanzania also reflected the difficulty of undoing the country's socialist legacy. Socialism was much more embedded in Tanzanian society when reforms began than was the case in Ghana. Tsikata (2001) also argues that domestic analytical capacities appear to have been stronger in Ghana than in Tanzania, although the latter had a strong Department of Economics at the University of Dar es Salaam.

\section{Model specification}

As the previous sections demonstrated, the last 50 years have seen turbulent changes and significant reforms in both countries. To obtain reliable estimates of key macroeconomic transmission mechanisms in Tanzania and Ghana is, therefore, a major econometric challenge. Extraordinary events usually result in large changes in the economic variables and can be highly influential for the results (Nielsen, 2008). It is, therefore, crucial that we are able to adequately control for the most important economic and political reforms discussed above. Also, over a period of such turbulent changes it is likely that the economic system has adjusted differently in the short- and the long-run which adds to the demands on the chosen econometric methodology. As in JMT14, we rely on the CVAR model which is tailor-made for the analysis of short-run and long-run structures in the data and allows for an elaborate use of intervention dummies to control for extraordinary events. Besides, it provides us with an analytical framework within which we can study similarities and dissimilarities between the two countries. One could say that it allows us to study the economic transmission mechanisms of each country through the same magnifying glass.

Section 3 demonstrated that for both countries, we can distinguish between a pre- and a post-reform period during which macroeconomic transmission mechanisms may differ. Such changes in regimes are not easy to reconcile with the assumption of constant parameters in the CVAR model. Yet, if we split the sample there are too few observations to apply the CVAR model. The full sample consists of only approximately 40 annual observations, and even with the full sample, a full-fledged CVAR analysis is barely doable. This poses an analytical challenge, which we address using dummies to account for extraordinary events and broken linear trends for significant changes in growth rates over the two regimes. Some of the structural changes can be accounted for in this way, but at least some of the coefficients to the stochastic variables are likely to measure average effects that in some cases may not be easy to interpret. In what follows we focus on the broad picture and accept the inherent limitations imposed by our data.

\subsection{The cointegrated VAR model}

Our CVAR model is similar to the one used in JMT14 where focus was on the long-run effect of aid on GDP, investment, private consumption and government consumption (all in real terms). Here we extend the analysis by including the real exchange rate as an open economy variable, and the inflation rate. ${ }^{3}$ This allows us to dig deeper and check whether the previous atypical results for Tanzania and Ghana are due to the ceteris paribus assumption that nominal and external factors in the economy are constant (or at least stationary) while in reality they are non-stationary.

Our baseline model is a $p$-dimensional VAR model with two lags:

$$
\Delta x_{t}=\Pi x_{t-1}+\Gamma_{1} \Delta x_{t-1}+\Phi D_{t}+\varepsilon_{t},
$$

where $\Pi$ is a $p \times p$ matrix describing long-run relationships among the variables, $\Gamma_{1}$ is a $p \times p$ matrix of short-run adjustment coefficients, $\Phi$ is a $p \times m$ matrix of coefficients, $x_{t}^{\prime}=\left[y_{t}\right.$, inv $_{t}, c_{t}, g_{t}$, aid $_{t}, \Delta p_{t}$, rex $\left._{t}\right]$, $D_{t}$ is a vector of $m$ deterministic components (such as constant, trend and dummies), and $\varepsilon_{t} \sim N i i d(0, \Omega)$ is a $p \times 1$ vector of error terms. Among the system variables $y_{t}$ is real GDP, inv $v_{t}$ is real investment, $c_{t}$ is real private consumption, $g_{t}$ is real government expenditure, ${ }^{4}$ aid $_{t}$ is real net ODA, rex $x_{t}$ is the real exchange rate relative to the US $\$,{ }^{5}$ and $\Delta p_{t}$ is the inflation rate. ${ }^{6}$ 
The real exchange rate is defined as $\operatorname{rex}_{t}=\log \left(s_{t} \times p^{*} / p\right)$ where $s_{t}$ is the domestic currency versus the US dollar rate and $p^{*} / p$ measures relative consumer prices between the United States and the domestic country. A rise/decline in the real exchange rate means depreciation/appreciation. Small letters denote logarithmic values of annual observations and $\Delta$ is the first difference operator. The effective sample period is 1967-2009 for Tanzania and 1968-2009 for Ghana.

In its baseline form, Equation (1) is basically a description of the covariances of the data given as a convenient formulation that allows us to discriminate between short- and long-term macroeconomic responses. The econometric task, called the general-to-specific approach, is to gradually impose statistically valid restrictions on the model parameters. This is a guarantee that the data are allowed to speak as freely and as precisely as possible about the macroeconomic mechanisms during the period in question.

If at least some of the variables $x_{t}$ are unit-root nonstationary then $\Pi$ in Equation (1) has reduced rank. This can be formulated as the hypothesis of cointegration:

$$
\Pi=\alpha \beta^{\prime}
$$

where $\alpha, \beta$ are $p \times r$ coefficient matrices and $r$ is the number of cointegration relations. If $\Gamma_{1}=0$ in Equation (1), the system will adjust back to equilibrium exclusively through $\alpha$ after it has been pushed away from equilibrium by an exogenous shock. When $\Gamma_{1} \neq 0$ the system also adjusts to lagged changes, $\Delta x_{t-1}$, so $\Gamma_{1}$ becomes part of the adjustment dynamics.

The advantage of the CVAR formulation compared to a regression analysis in levels is that by transforming the trending variables, $x_{t}$, into stationary differences, $\Delta x_{t}$, and stationary cointegration relations, $\beta^{\prime} x_{t}$, the usual multicollinearity problem is effectively addressed. For example:

(i) Multicollinearity between the $x$ variables does not lead to imprecise estimates of the cointegration relations, $\beta^{\prime} x_{t}$. This is because two variables are cointegrated only if they share a common stochastic trend defined as the accumulation of all permanent shocks that have pushed the variables out of equilibrium. While, for example, cointegration between two unrelated random walks will be rejected with high probability, they may have a correlation coefficient close to one in small samples (Johansen, 2012). Also, the cointegration coefficients are 'canonical' in the sense of being invariant to increasing the information set, or to changing the direction of minimisation.

(ii) The removal of trends, either by differencing or cointegration, is likely to make the multicollinearity between $\Delta x_{t}$ and $\beta^{\prime} x_{t}$ almost disappear. When $x_{t} \sim I(1),>\Delta x_{t}>$ and $\beta^{\prime} x_{t}$ are stationary, standard inference on $\left(\alpha, \Gamma_{1}, \Sigma\right)$ applies for a given $\beta$.

Thus, it is the explicit separation between short-run and long-run effects, made possible by cointegration, that makes inference from a CVAR model reliable. To illustrate, the subsequent empirical models explain 65-80 per cent of the annual variation of the macrodata for Tanzania and 62-84 per cent for Ghana. This allows us to answer economic questions of significant interest with a high degree of precision.

\subsection{Controlling for major structural reforms}

To control for the effect of extraordinary events on the variables that have caused long-run trends to change and growth rates and equilibrium means to shift to a new level, we introduce a number of deterministic terms, $D_{t}$, defined as:

$$
D_{t}=\mu_{0}+\mu_{01} D s_{x x}+\mu_{1} t+\mu_{11} t_{x x}+\phi D p_{x x}
$$


where $\mu_{0}$ is a constant, $D s_{x x}$ is a the step dummy, defined as $(0, \ldots, 0,0,1,1,1,1 \ldots, 1)$ with the step starting in year $19 \mathrm{xx}, t$ is a linear trend, $t_{x x}$ is a linear trend defined as $(0, \ldots, 0,0,1,2,3,4, \ldots)$ and $D p_{x x}$ is an impulse dummy defined as $(0, \ldots, 0,0,1,0,0,0 \ldots, 0)$, where $x x$ stands for the year $19 \mathrm{xx}$.

The CVAR captures the long-run and short-run structures in the same model implying that the effect of an extraordinary event will differ between the short-run dynamics and the long-run relations. Hence, the coefficients $\left(\mu_{0}, \mu_{01}, \mu_{1}, \mu_{11}, \phi\right)$ have to be decomposed into one part belonging to the short-run structure and another belonging to the long-run relations (Juselius, 2006, Chapter 6). Accordingly, the constant and the step dummy are decomposed as $\mu_{0}=\alpha \beta_{0}+\gamma_{0}$ and $\mu_{01}=\alpha \beta_{01}+\gamma_{01}$. The $\alpha$ components, $\beta_{0}+\beta_{01} D s_{x x}$, describe a change in the equilibrium mean at the year 19xx and the other parts, $\gamma_{0}+\gamma_{01} D s_{x x}$, a change in the slope coefficient of the linear trend at 19xx.

The broken linear trend, $\mu_{1} t=\alpha \beta_{1} t$ and $\mu_{11} t_{x x}=\alpha \beta_{11} t_{x x}$, is restricted to the cointegration relations to avoid quadratic trends in the data. Thus, the long-run relations (the cointegration relations) can be trend-stationary around a linear trend with a changing slope coefficient at 19xx. This gives us some extra flexibility to capture features in the data that would, as already noted, otherwise be difficult to model given the econometric constraint imposed upon us by the limited number of observations over a period with very dramatic changes.

For Tanzania, the graphical analysis suggested that the slopes of the long-run linear trends in GDP, private consumption, government expenditure, and investment were approximately constant over the full period. The long-run trend in aid can also be assumed reasonably constant provided we control for a level shift in the period 1973-1992 (when aid was roughly 100 per cent above its long-run level). Since the increase in aid did not lead to a proportional increase in GDP we have controlled for this expansion through the inclusion of two step dummies, $D s_{73, t}$ and $D s_{92, t}$, restricted to be in the cointegration relations. This is to safeguard against a bias of the estimated effect of aid on the macroeconomy, in particular for the second half of the sample when aid was no longer above its long-run trend. Finally, we have included an impulse dummy, $D p_{85, t}$ to control for the big devaluation of the Tanzanian currency in 1985.

With these additions, the final specification of the empirical CVAR model for Tanzania becomes:

$$
\Delta X_{t}=\alpha \widetilde{\beta}^{\prime} \tilde{X}_{t-1}+\Gamma_{1} \Delta X_{t-1}+\mu_{0}+\varphi_{1} D p_{73}+\varphi_{2} D p_{85}+\varphi_{3} D p_{92}+\varepsilon_{t}
$$

where $\widetilde{X}_{t-1}=\left(X_{t-1}, D s_{73, t}, D s_{92, t}, t,\right)$ and $\widetilde{\beta}^{\prime}=\left(\beta^{\prime}, \beta_{01}, \beta_{02}\right)$.

For Ghana, 1983 defines a separation between a period of a stagnant economy with low growth rates and a reform period with vibrant economic growth. As the graphical analysis showed, only government expenditures exhibited linear growth in the first more controlled regime, whereas linear growth was resumed for all variables in the more liberal, post-reform regime.

To control for the regime shift, we allow for a broken linear trend, $\beta_{1} t+\beta_{11} t_{83}$, in the long-run relations combined with an unrestricted step dummy, $D s_{83}$. Together they are able to account for the change in the growth rates and the shift in the equilibrium mean of the long-run relations. Except for an unrestricted impulse dummy $D p_{72}$ to control for a large drop in investment in 1972 due to Ghana's unilateral repudiation of external debt, the division into a pre- and a post-reform period is sufficient to obtain a reasonably well-specified model. The 1972 event also caused a decline in foreign aid and government investment.

For Ghana the final CVAR specification is:

$$
\Delta X_{t}=\alpha \widetilde{\beta}^{\prime} \widetilde{X}_{t-1}+\Gamma_{1} \Delta X_{t-1}+\mu_{0}+\mu_{01} D s_{83}+\varphi_{1} D p_{72}+\varepsilon_{t}
$$

where $\widetilde{X}_{t-1}=\left(X_{t-1}, t, t_{83}\right)$ and $\widetilde{\beta}^{\prime}=\left(\beta^{\prime}, \beta_{1}, \beta_{11}\right)$

Various diagnostic misspecification tests are reported in Appendix Tables A1 and A2. Normality is accepted for both countries and there is no significant residual autocorrelation of order one or two in either country. With the exception of private consumption for Tanzania, there are no significant 
AutoRegressive Conditional Heteroskedasticity (ARCH) effects. This is reassuring as the CVAR model seems robust to moderate levels of ARCH effects (Gonzalo, 1994).

After having controlled for the effect of some of the most crucial institutional events the specification of the CVAR model became statistically acceptable as can be verified from Table A1 in the Appendix. Except for the inflation rate equation, the misspecification tests are in general reasonable. As the inflation rate can be shown to be weakly exogenous, ${ }^{7}$ this moderate misspecification should not be of any concern. It needs to be emphasised, though, that Tanzania and Ghana were subject to many additional economic and political changes over the sample period and the constant parameter assumption underlying the CVAR model is unlikely to be completely satisfied. Since there are too few annual observations to split the sample into a greater number of homogeneous regimes, it is important to keep in mind that the estimated coefficients describe average historical effects between two very different pre- and post-reform regimes rather than deep structural parameters. This is likely to cause large standard errors of coefficients, so we reiterate that some inferences are likely to be imprecise. This is aggravated by data which are in some cases of poor quality.

\subsection{The common trends representation}

The decomposition of the data into deterministic and stochastic trends is based on the moving average representation of the CVAR model:

$$
\begin{gathered}
X_{t}=C \sum_{i=1}^{t}\left(\varepsilon_{i}+\mu_{0}+\mu_{01} D s_{x x, t}+\varphi_{p} D p_{x x, t}\right)+ \\
+C^{*}(L)\left\{\varepsilon_{i}+\alpha\left(\beta_{0}+\beta_{01} D s_{x x, t}+\beta_{1} t+\beta_{11} t_{x x}\right)\right\}+\tilde{X}_{0}
\end{gathered}
$$

where, $C=\beta_{\perp}\left(\alpha_{\perp}^{\prime} \Gamma \beta_{\perp}\right)^{-1} \alpha_{\perp}^{\prime}, C^{*}(L)$ is a lag polynomial describing impulse response effects, $\tilde{X}_{0}$ is a catch-all for initial values, and

$$
C=\beta_{\perp}\left(\alpha_{\perp}^{\prime} \Gamma \beta_{\perp}\right)^{-1} \alpha_{\perp}^{\prime}
$$

is a $p \times p$ long-run impact matrix with rank $p-r{ }^{8}$ The $p-r$ common stochastic trends are measured by $\alpha_{\perp}^{\prime} \sum_{i=1}^{t} \varepsilon_{i}$ and they affect the variables by the loadings $\tilde{\beta}_{\perp}=\beta_{\perp}\left(\alpha_{\perp}^{\prime} \Gamma \beta_{\perp}\right)^{-1}$. The shocks $\varepsilon_{t}^{\prime}=$ $\left[\varepsilon_{y}, \varepsilon_{i n v}, \varepsilon_{a}, \varepsilon_{r e x}, \varepsilon_{c}, \varepsilon_{g}, \varepsilon_{\Delta p}\right]$ are measured by the estimated residuals in the CVAR model.

The coefficients $\alpha_{\perp}$ allow us to attach weights to the individual shocks that have cumulated to stochastic trends in the data. By focussing on significant coefficients we can get a broad picture of which shocks have been particularly important. For example, was it an inflation shock or a shock to government expenditure that pushed the economy out of equilibrium? It is, however, important to note that the estimated results may be strongly affected by the choice of economic variables and the specification of the deterministic components. Therefore, estimated stochastic trends are likely to change if the specification of economic and dummy variables changes. Different sets of economic variables, $x_{t}$, will explain the variation of the system to varying degrees; and different sets of deterministic components, $D_{t}$, will change the decomposition into deterministic and stochastic explanatory power. In this sense, a residual is not an estimate of a structural shock, unless the model is complete, something which is seldom the case. Therefore, we consider the empirical results to give us one perspective on the two economies (Hoover, 2012) given by the choice of sample period and statistical model, the latter defined by its stochastic and deterministic specification. This is an important caveat when comparing our results here with the findings in JMT14. 


\section{Cointegration rank determination}

The choice of cointegration rank determines the division into the $r$ long-run equilibrium relations towards which the system adjusts and the $p-r$ common stochastic trends which push the system away from equilibrium. Formally, the likelihood ratio trace test is used to determine the number of the cointegration rank (Johansen, 1996). However, when the number of observations is as small as in the present study, the asymptotic distribution of the trace test suffers from both size and power problems. While the size problem can be solved using the Bartlett corrected trace test statistics (Johansen, 2002), the problem associated with low power to reject an incorrect unit root remains (Hendry \& Juselius, 2000; Juselius, 2006). The latter makes the trace test less useful, in particular when the null of stationarity (rather than nonstationarity) is more relevant from an economic point of view, as discussed by Juselius (2006, Chapter 8.5).

Rather than just using the trace test, we therefore base the choice of rank on the characteristic roots of the model, the significance of the $\alpha$ coefficients, and the graphs of cointegration relations. In addition, and most importantly, we assess the statistical evidence against a plausible economic scenario for the data generating mechanisms over this period: a priori, we expect the system variables to be affected by long-run trends associated with trends in population and productivity proxied by the deterministic trends. We also expect at most two stochastic trends, one capturing the nominal growth over the period, the other describing medium long-run business cycle movements in the data. On this background our preferred rank is five and we shall assess the statistical evidence against this number. ${ }^{9}$

Table 1 reports the largest unrestricted characteristic root, $\hat{\rho}_{\max }$, for the given rank, $r^{*} \pm 1$, and the largest t-value of the $\alpha_{r}$ coefficients, $t_{\max }$, of the $r^{\text {th }}$ cointegration relation. The preferred cointegration rank, $r^{*}$, is as noted five in both countries, but as a sensitivity check we report as well the results for the closest alternatives, $r=4,6$. For Tanzania, the information criteria are rather similar and hence not very informative: the characteristic roots are quite similar in all three cases but the significant error correction coefficients of the fifth cointegration relation can be used to justify our preferred rank. For Ghana, the choice of rank was more straightforward: both the characteristic roots and the significance of error correction coefficients suggested a cointegration rank of five. This reinforces our final choice of rank five for both Tanzania and Ghana.

\section{The pushing forces}

Figures 1-4 in Section 2 depicted graphically the decomposition of the macrovariables into long-run deterministic trends and stochastic deviations from these trends.

According to Equation (6), the main exogenous drivers in the period under study are the deterministic trend, capturing long-term trends in factor productivity and population, and the stochastic trends capturing persistent medium-long-run movements in the economy. Section 4.3 argued that the latter can be treated as medium-run stochastic trends around long-run growth trends describing the cumulated effects of exogenous shocks to the economy that have pushed the macrovariables out of equilibrium for prolonged periods of time.

\subsection{The two stochastic trends}

The common stochastic trends, $\alpha_{\perp}^{\prime} \sum^{\varepsilon_{i}}$, and their loadings, $\tilde{\beta}_{\perp}$, are reported in Table 2 . For both countries, one of the common trends basically describes cumulated shocks to the inflation rate. This

Table 1. The largest characteristic roots and maximum t-values of for different values of $r$

\begin{tabular}{llclll}
\hline & Tanzania & & \multicolumn{2}{c}{ Ghana } \\
\cline { 5 - 6 }$r$ & $\hat{\rho}_{\max }$ & $t_{\max }$ of $\alpha_{r}$ & $r$ & $\hat{\rho}_{\max }$ & $t_{\max }$ of $\alpha_{r}$ \\
\hline 4 & 0.78 & 6.6 & 4 & 0.76 & 5.67 \\
$r^{*}=5$ & $\mathbf{0 . 8 2}$ & $\mathbf{3 . 9}$ & $r^{*}=5$ & $\mathbf{0 . 6 9}$ & $\mathbf{4 . 2 7}$ \\
6 & 0.84 & 3.1 & 6 & 1.03 & 1.64 \\
\hline
\end{tabular}


Table 2. The common stochastic trends and their loadings

\begin{tabular}{|c|c|c|c|c|c|c|c|}
\hline & $y$ & inv & $a$ & rex & $c$ & $g$ & $\Delta p$ \\
\hline \multicolumn{8}{|c|}{ Tanzania } \\
\hline$\alpha_{\perp, 1}^{\prime}$ & 0.00 & $*$ & $*$ & 0.12 [1.19] & $*$ & $*$ & $\mathbf{1 . 0 0}[N A]$ \\
\hline$\tilde{\beta}_{\perp, 1}^{\prime}, 1$ & $\mathbf{- 0 . 5 3}[-3.09]$ & $-1.99[-3.54]$ & $-\mathbf{0 . 8 3}[-2.48]$ & $1.23[3.20]$ & $*$ & $-1.85[-1.67]$ & $\mathbf{0 . 8 6}[3.44]$ \\
\hline$\alpha_{\perp, 2}^{\prime}$ & 1.00 & $\mathbf{- 0 . 3 0}[-3.88]$ & $0.08[1.82]$ & $*$ & $-\mathbf{0 . 4 1}[-3.97]$ & 0.09 [1.39] & 0.00 \\
\hline$\tilde{\beta}_{\perp, 2}^{\prime}$ & $0.73[1.85]$ & $*$ & $1.79[2.33]$ & $-1.52[-1.72]$ & $\mathbf{- 0 . 8 9}[-2.49]$ & $6.69[2.61]$ & $*$ \\
\hline \multicolumn{8}{|c|}{ Ghana } \\
\hline$\alpha_{\perp, 1}^{\prime}$ & 0.00 & * & * & $*$ & $1.66[1.74]$ & $*$ & 1.00 \\
\hline$\tilde{\beta}_{\perp, 1}^{\prime}$ & $*$ & $\mathbf{1 . 0 7}[2.36]$ & $0.34[1.68]$ & $-0.27[-2.07]$ & $\mathbf{0 . 1 8}[2.00]$ & $-0.16[-1.64]$ & 0.39 [1.87] \\
\hline$\alpha_{\perp, 2}^{\prime}$ & 1.00 & -0.28 & $\mathbf{0 . 2 4}[2.90]$ & $-0.25[-3.05]$ & $\mathbf{0 . 9 0}[2.17]$ & $\mathbf{- 0 . 6 4}[-2.84]$ & 0.00 \\
\hline$\tilde{\beta}_{\perp, 2}^{\prime}$ & $0.35[3.62]$ & * & $\mathbf{0 . 7 7}[2.68]$ & $-\mathbf{0 . 3 4}[-1.83]$ & 0.25 [2.01] & $-\mathbf{0 . 3 9}[-2.73]$ & $\mathbf{- 0 . 7 0}[-2.33]$ \\
\hline
\end{tabular}

Notes: Coefficients with a $t$-ratio $>1.96$ are in bold face and with a $t$-ratio $<1.0$ are replaced with *. $t$-ratios are in brackets.

interpretation is supported by the test of weak exogeneity in the Appendix, Table A2. Altogether it implies that inflation has not been equilibrium error correcting to the macroeconomic conditions but, instead, has been exogenously determined by factors outside the information set, such as excessive expansions of money supply to finance government expenditures. ${ }^{10}$ Ghana in particular seems to have used this option during the pre-reform period, whereas generous aid to Tanzania during the Nyerere period lessened such a need.

The second common trend captures shocks to income relative to investment and private consumption in Tanzania and to income relative to investment and government expenditure in Ghana. In addition, shocks to private consumption, aid and the real exchange rate are also significant for Ghana. Altogether the second stochastic trend seems to capture medium-long-run movements in the real economy.

While the trends are somewhat similar between the two countries, this is not the case with their loadings. In particular, the final impact of an inflation shock on the system is totally different for the two countries. The coefficients are of opposite signs with the exception of the coefficients to government expenditure, which were negative in both cases. More specifically, an inflation shock had a significant negative final impact on (i) Tanzanian GDP (insignificant in Ghana), (ii) Tanzanian investment (positive in Ghana), and (iii) Tanzanian aid (positive but barely significant in Ghana). It had no effect on Tanzanian private consumption (positive in Ghana), and it caused a real appreciation in Tanzania, but a real depreciation in Ghana. Altogether these results seem more plausible for Tanzania than for Ghana. One reason is that the estimated final impacts may represent average effects over two regimes, which in the case of Ghana were radically different.

In contrast, the final impacts of a real shock on the system are more similar. For example, the impact is positive for both GDP and aid in both countries and it also caused a real appreciation in both countries. Furthermore, a real shock had a negative long-run impact on inflation in Ghana but no significant effect in Tanzania. Regarding private consumption and government expenditure the effects differ in the sense that the former is negative in Tanzania but positive in Ghana, whereas the latter is positive in Tanzania but negative in Ghana. Thus, in both countries there seems to be strong substitutions between private consumption and government expenditure, but in Tanzania it is the government expenditure that has benefitted from a real shock at the expense of private consumption. In Ghana it is the opposite.

In addition, for Tanzania, the coefficients to GDP and consumption are of similar magnitudes with opposite signs which can be interpreted to mean that a real shock has a negative effect on the consumption-income ratio or equivalently a positive effect on savings. For Ghana the coefficients to GDP and government expenditure are similar with opposite signs which suggests that a real shock has had a negative effect on the government expenditure-income ratio. 


\subsection{The final impact of shocks to the system}

To study the individual effects, Table 3 reports the estimates of the final impact of a shock to each variable, $\hat{\varepsilon}_{x}$, on the system. As the inflation rate was found to be weakly exogenous and, hence, a common stochastic trend in itself, the last column of the table corresponds roughly to $\hat{\beta}_{\perp 1}$ in Table 2 . The remaining columns allow us to study the underlying sources of the real stochastic trend in more detail.

We shall first focus on the final effect of a shock to aid and to the real exchange rate on the system. For Tanzania, the final impact of a shock to these two variables is mostly insignificant whereas for Ghana it is mostly significant. While in both countries the final impact of a shock to aid has been a real appreciation of the currency of the same magnitude, it has been positive for private consumption and negative for government expenditure in Tanzania. The opposite is the case for Ghana. For both countries the final impact of aid is positive for GDP (and strongly significant in Ghana) and positive but insignificant for investment. Thus, by extending the dataset with the real exchange rate and the inflation rate, the negative (and significant) long-run impact of aid on investment in Ghana found in JMT14 is no longer present. This result is robust to the slight change in sample period and in the specification of deterministic variables compared to JMT14. For Tanzania, the long-run impact of aid on GDP and investment did not change much but, as shall become evident in the next section, adding the real exchange rate and the inflation rate is crucial for understanding why these long-run impacts are insignificant. $^{11}$

For Ghana, the final impact of a shock to the real exchange rate (a depreciation) has been negative for GDP and private consumption, but positive for government expenditure. In both countries, it has been positive for inflation reflecting the experience of increasing inflation rates together with an appreciating currency in the pre-reform period and decreasing inflation rates together with a depreciating currency in the reform period. The final impact of shocks to government expenditure is mostly insignificant for both countries, except for a positive effect on inflation and a negative effect on GDP growth in Ghana. This supports the interpretation suggested by review of WDI data on domestic credit to the government that government expenditures were financed by monetary expansion, hence increasing inflation and lowering growth in the first period, followed by a stricter monetary discipline in the second period and declining inflation rates and higher growth.

To summarise, by including the real exchange rate and inflation to the five variable system of JMT14, the final impacts of foreign aid on GDP and investment turn positive, albeit not all are highly significant. The results also show that a shock to foreign aid caused the real exchange rate to appreciate, suggesting

Table 3. The long-run impact matrix $\mathrm{C}$ for Tanzania and Ghana

\begin{tabular}{|c|c|c|c|c|c|c|c|}
\hline & $\hat{\varepsilon}_{y}$ & $\hat{\varepsilon}_{i n v}$ & $\hat{\varepsilon}_{\text {aid }}$ & $\hat{\varepsilon}_{r e x}$ & $\hat{\varepsilon}_{c}$ & $\hat{\varepsilon}_{g}$ & $\hat{\varepsilon}_{\Delta p}$ \\
\hline \multicolumn{8}{|c|}{ Tanzania } \\
\hline$y_{t}$ & $0.73[1.85]$ & $-0.17[-1.67]$ & $0.06[1.24]$ & $*$ & $-0.27[-1.61]$ & $0.09[1.63]$ & $\mathbf{- 0 . 5 3}[-3.09]$ \\
\hline inv $_{t}$ & $*$ & $*$ & $*$ & $*$ & $*$ & $*$ & $\mathbf{- 1 . 9 9}[-3.54]$ \\
\hline aid $_{t}$ & $\mathbf{1 . 7 9}[2.33]$ & $-\mathbf{0 . 4 6}[-2.34]$ & $0.14[1.52]$ & $*$ & $-\mathbf{0 . 6 9}[-2.10]$ & $0.19[1.86]$ & $-\mathbf{0 . 8 3}[-2.48]$ \\
\hline $\operatorname{rex}_{t}$ & $-1.52[-1.72]$ & $0.14[1.52]$ & $-0.12[-1.17]$ & $*$ & $0.56[1.49]$ & $-0.19[-1.57]$ & $\mathbf{1 . 2 3}[3.20]$ \\
\hline$c_{t}$ & $\mathbf{- 0 . 8 9}[-2.49]$ & $0.27[3.04]$ & $-0.07[-1.54]$ & * & $\mathbf{0 . 3 7}[2.41]$ & $-0.07[-1.54]$ & $*$ \\
\hline$g_{t}$ & $\mathbf{6 . 6 9}[2.61]$ & $\mathbf{- 1 . 8 3}[-2.81]$ & $0.52[1.68]$ & $*$ & $\mathbf{- 2 . 6 4}[-2.42]$ & $0.67[1.93]$ & $-1.85[-1.67]$ \\
\hline$\Delta p_{t}$ & $*$ & $*$ & $*$ & $0.10[1.21]$ & $*$ & $*$ & $\mathbf{0 . 8 6}[3.44]$ \\
\hline \multicolumn{8}{|c|}{ Ghana } \\
\hline$y_{t}$ & $\mathbf{0 . 3 5}[3.62]$ & $-0.10[-1.87]$ & $\mathbf{0 . 0 9}[4.10]$ & $-\mathbf{0 . 0 9}[-3.23]$ & $\mathbf{0 . 3 9}[2.36]$ & $-0.21[-2.59]$ & $*$ \\
\hline$i n v_{t}$ & * & $*$ & $0.19[1.23]$ & $*$ & $1.86[1.66]$ & $*$ & $\mathbf{1 . 0 7}[2.36]$ \\
\hline $\operatorname{aid}_{t}$ & $\mathbf{0 . 7 7}[2.68]$ & $-0.25[-1.51]$ & $\mathbf{0 . 2 4}[3.55]$ & $\mathbf{- 0 . 1 8}[-2.26]$ & $\mathbf{1 . 2 5}[2.52]$ & $-0.41[-1.69]$ & $0.34[1.68]$ \\
\hline $\operatorname{rex}_{t}$ & $-0.34[-1.83]$ & $*$ & $\mathbf{- 0 . 1 2}[-2.85]$ & $0.07[1.45]$ & $\mathbf{- 0 . 7 5}[-2.34]$ & $*$ & $-\mathbf{0 . 2 7}[-2.07]$ \\
\hline$c_{t}$ & $\mathbf{0 . 2 5}[2.01]$ & $-0.09[-1.22]$ & $\mathbf{0 . 0 9}[3.01]$ & $-0.06[-1.62]$ & $\mathbf{0 . 5 2}[2.39]$ & $-0.12[-1.12]$ & $\mathbf{0 . 1 8}[2.00]$ \\
\hline$g_{t}$ & $-\mathbf{0 . 3 9}[-2.73]$ & $0.12[1.54]$ & $\mathbf{- 0 . 1 2}[-3.59]$ & $\mathbf{0 . 0 9}[2.32]$ & $\mathbf{- 0 . 6 2}[-2.52]$ & $0.21[1.74]$ & $-0.16[-1.64]$ \\
\hline$\Delta p_{t}$ & $\mathbf{- 0 . 7 0}[-2.33]$ & * & $-0.11[-1.59]$ & $\mathbf{0 . 1 9}[2.33]$ & & $\mathbf{0 . 5 5}[2.14]$ & $0.39[1.87]$ \\
\hline
\end{tabular}

Notes: Coefficients with a $t$-ratio $>1.96$ are in bold face and with a $t$-ratio $<1.0$ are replaced with *. $t$-ratios are in brackets. 
presence of a Dutch disease effect, and finally that macroeconomic shocks have systematically had opposite effects on private consumption and government expenditure in the two countries.

\section{Pulling forces}

This section provides estimates of the role of real exchange rate persistence, inflation and aid in the macroeconomic transmission mechanisms. The idea is to pin down similarities and dissimilarities between the two countries in order to study how the transmission mechanisms have differed and if possible relate the differences to differences in policy. We achieve this by estimating an identified structure of five cointegration relations (Johansen, 1995; Johansen \& Juselius, 1994) and by studying how the system had adjusted when exogenous shocks pushed the system out of equilibrium (Juselius, 2006).

\subsection{Identification of irreducible cointegration relations}

An identified cointegration structure consists of $r$ irreducible cointegration relations, where irreducibility implies that stationarity is lost if one of the variables is omitted from the relation (Davidson, 1998). Hence, they contain exactly the right number of variables needed to make the relation stationary, no less, no more. The results are interpreted with the following caveats:

(i) A cointegration relation is expressed as a deviation from a long-run value and, therefore, corresponds to an equilibrium error. However, to ease the interpretation, we shall express the cointegration relations in the form of equilibrium relations rather than equilibrium errors when discussing the results.

(ii) Cointegration as such only tells us that the variables have been co-moving over time and does not say anything about causality unless combined with the adjustment coefficients $\alpha$ and economic identification is generally incomplete without combining the two. For example, $\left(x_{1, t}-\beta_{1} x_{2, t}\right) \sim I(0)$ tells us that the two variables are positively co-moving. If the adjustment coefficient $\alpha_{1}$, of $\Delta x_{1, t}$ is significantly negative then $x_{1, t}$ has been equilibrium correcting and if, in addition, $\alpha_{2}$ of $\Delta x_{2, t}$ is insignificant we may conclude that the direction of causality is from $x_{2, t}$ to $x_{1, t}$. If instead $\alpha_{2}$ is positive and significant then both variables are equilibrium correcting signifying simultaneous feedback. In general we choose to normalise on a $\beta$ variable that is significantly equilibrium correcting in $\alpha$. This is different from a traditional simultaneous equation model where causality is assumed by the choice of an endogenous variable for each of the equations of the system.

(iii) There are usually several ways of identifying a structure of irreducible cointegration relations. For example, if $x_{1, t}, x_{2, t}, x_{3, t}$ share one common trend, then $x_{1, t}-x_{2, t}, x_{2, t}-x_{3, t}$ and $x_{1, t}-x_{3, t}$ are irreducible cointegration relations. Then the two relations in the long-run structure can be identified by either $\left(x_{1, t}-x_{2, t}, x_{2, t}-x_{3, t}\right)$ or $\left(x_{1, t}-x_{2, t}, x_{1, t}-x_{3, t}\right)$.

(iv) The number of irreducible relations needs not be the same as the number of postulated economic relations implying that a cointegration relation does not necessarily correspond directly to a hypothetical economic relation. For instance, a linear combination of two irreducible cointegration relations tied together with the $\alpha$ coefficients can be a closer estimate of such a relation. In this sense, a generically identified structure of $r$ irreducible cointegration relations, $\beta^{\prime} x_{t}$, can be thought of as building blocks that can be used to construct meaningful economic relations with the help of the $\alpha$ coefficients.

(v) A cointegration relation among three or more variables may not be easy to interpret in terms of sign effects. For example $\left(\beta_{1} x_{1, t}-\beta_{2} x_{2, t}-\beta_{3} x_{3, t}\right) \sim I(0)$ may mean that $x_{1, t}$ is positively associated with both $x_{2, t}$ and $x_{3, t}$. But another interpretation is that $x_{2, t}$ is positively associated with $x_{1, t}$ but negatively with $x_{3, t}$. This of course is similar to regressing $x_{1, t}$ on $x_{2, t}$ and $x_{3, t}$ contra regressing $x_{2, t}$ on $x_{1, t}$ and $x_{3, t}$, the difference being that the cointegration coefficients are invariant to the choice of normalising variable in contrast to the regression coefficients. 
(vi) Deterministic components such as a linear trend or a dummy variable cannot in general be associated with a specific stochastic variable unless the cointegration relation contains just one variable. For example, if $x_{1, t}$ and a linear trend are cointegrated, then trend-adjusted $x_{1, t}$ is stationary. Similarly if $x_{1, t}$ and a step dummy are cointegrated then $x_{1, t}$ is stationary with a shift in the mean. But, if the cointegration relation consists of a trend and several trending variables, say $x_{1, t}$ and $x_{2, t}$, then this implies cointegration between $\left(x_{1, t}-b_{1} t\right)$ and $\left(x_{2, t}-b_{2} t\right)$. If the cointegration relation consists of a trend, $t$, two trending variables, $x_{1, t}$ and $x_{2, t}$, and a nontrending variable, $x_{3, t}$, then the interpretation is that $x_{3, t}$ and the trend-adjusted variables $\left(x_{1, t}-b_{1} t\right)$ and $\left(x_{2, t}-b_{2} t\right)$ are cointegrated.

(vii) A cointegration relation among trending variables that does not need a trend can often be given an interpretation as a deviation from a long-run economic steady-state relation, provided it satisfies economic identification as defined in Johansen and Juselius (1994). If, on the other hand, a cointegration relation contains a linear trend, it can often be given an interpretation as a relationship describing medium long-run deviations from the the long-run trend, sometimes reflecting persistent cycles coinciding with different political and economic regimes or as in the African case, as a result of terms of trade shocks, political mismanagement, long-lasting droughts.

(viii) A cointegration relation between a real variable and inflation rate, for example real exchange rate and inflation, can be interpreted as a medium long-run adjustment relation in the following sense: assume that $\Delta p_{t}+\beta_{1}\left(s_{t}-p_{t}-p_{t}^{*}\right)$ is a cointegration relation which can be reformulated as $\Delta p_{t}=-\beta_{1}\left(s_{t}-p_{t}-p_{t}^{*}\right)+u_{t}$ where $s_{t}-p_{t}-p_{t}^{*}=\operatorname{rex}_{t}$ and $u_{t}$ is stationary. If $\beta_{1}<0$, then $\Delta p_{t}$ is equilibrium error correcting to the real exchange rate, whereas if $\beta_{1}>0$, then $\Delta p_{t}$ is equilibrium error increasing over the medium run.

With these caveats in mind we proceed to interpret the empirical results in the next section.

\subsection{A long-run structure for Tanzania}

The results for Tanzania are reported in Table 4 where insignificant adjustment coefficients have been replaced by the symbol $*$ and are not commented on. According to caveat vii, cointegration relations 1-3 represent long-run steady-state relations, whereas 4 and 5 reflect medium-long-run relations.

Real GDP is equilibrium correcting to the first relation $(-0.12)$ and we interpret it as a relation for real aggregate income (caveat $i$ ):

$$
\underset{(-0.12)}{y_{t}}=0.62 \operatorname{inv}_{t}+1.23 \Delta p_{t}+0.28 D_{s, 92, t}
$$

The results show that real GDP, investment and inflation have been positively co-moving. The positive inflation effect may seem puzzling but would be perfectly interpretable if we had normalised on investment instead. In this case investment would have been positively related to GDP and negatively to inflation (caveat $v$ ). Since Table 4 shows that investment was not significantly equilibrium correcting to this relation, we have nonetheless chosen to normalise on GDP (caveat ii). Both income and investment are trending variables that were cointegrated without needing a trend and Equation (9) can therefore be interpreted as an average long-run equilibrium relationship (caveat vi). The coefficient 0.62 reflects the fact that investment grew faster than GDP in this period, a result that deserves further study. The step dummy captures a positive shift in the level of GDP in 1992 or alternatively a negative shift in inflation or investment (caveat vi). The $\alpha$ coefficients show that when GDP was above its equilibrium value, the real exchange rate appreciated (a Dutch disease effect), and aid and government expenditure increased, whereas private consumption decreased (describing strong substitution effects between private consumption and government expenditure).

Investment is significantly equilibrium correcting to the second relation $(-0.28)$, hence it is interpreted as an investment relation (caveat $i$ ): 
Foreign aid in Tanzania and Ghana 1093

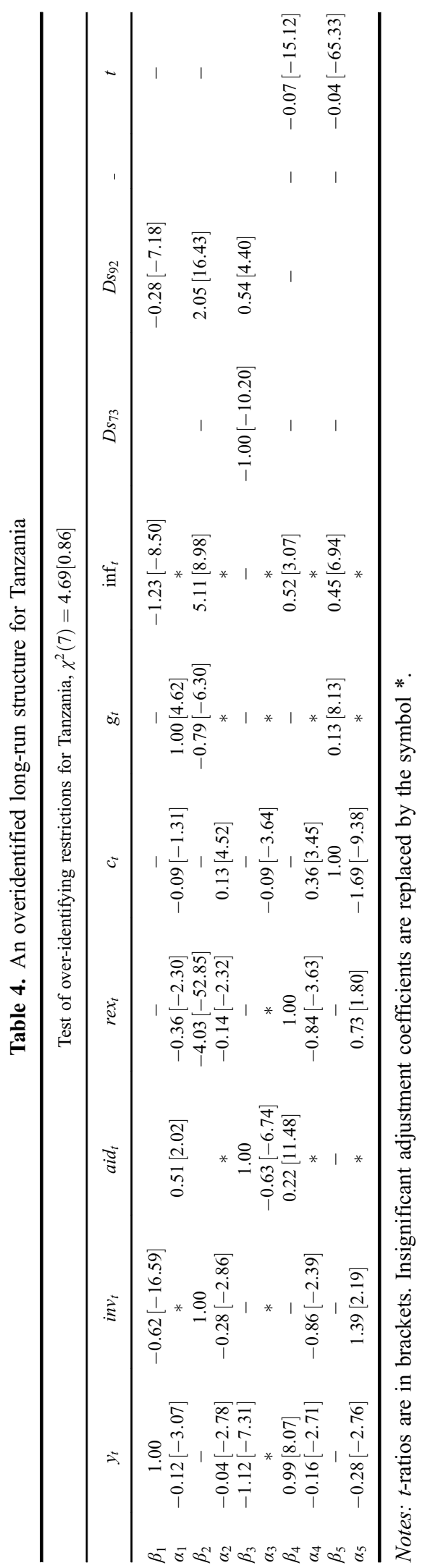




$$
\underset{(-0.28)}{\operatorname{inv}} v_{t}=4.03 r e x_{t}+0.79 g_{t}-5.11 \Delta p_{t}-2.05 D_{s, 92, t},
$$

The estimates show that investment increased when the currency depreciated and when government expenditure increased, whereas it decreased with increasing inflation. Since investment and government consumption are both trending variables and no trend was needed in Equation (10), it is interpreted as a long-run relationship (caveat $v i$ ). The positive coefficient to rex $_{t}$ and the negative coefficient to $\Delta p_{t}$ is consistent with error increasing behaviour between the two in the medium run (caveat viii). The 1992 level shift can be associated with any of the variables (caveat vi), for example a downward shift in investment or inflation or an upward shift in government expenditure or any combination had. The $\alpha$ coefficients show that the real exchange rate has been error increasing, implying that, in the short run, the real exchange rate has appreciated when investment has been above its equilibrium value. The latter stands in contrast to the positive long-run relationship between investment and the real exchange rate implying that over the long-run investment has increased when the currency has depreciated. Finally, private consumption has adjusted positively to this relation.

The third relation is equilibrium correcting in aid $(-0.63)$ and, hence, is interpreted as an aid relation (caveat $i i$ ):

$$
\underset{(-0.63)}{\operatorname{aid}_{t}}=1.12 y_{t}+1.00 D s_{73_{t}}-0.54 D s_{92, t}
$$

The estimates show that aid has been increasing with increasing GDP. The two step dummies show that the level of log aid roughly doubled in 1973 and halved in 1992. The $\alpha$ coefficients show that private consumption has fallen when aid has been above its long-run equilibrium value.

Both the real exchange rate and the real GDP are equilibrium error correcting to the fourth relation suggesting simultaneous feedback (caveat $i$ ). Since the real exchange rate is more strongly adjusting we choose to interpret it as a real exchange rate relation:

$$
\underset{(-0.84)}{\operatorname{rex}_{t}}=-0.99 \hat{y}_{t}-0.22 \widehat{\operatorname{aid}}_{t}
$$

where $\hat{x}_{t}$ stands for $x_{t}$ corrected for its long-run trend. Thus, the relation can be interpreted as a medium long-run relationship describing that the real exchange rate has shown a tendency to appreciate when GDP and/or aid have been above its long-run trend (caveat $v i$ ). This lends support to the hypothesis that it was the expansion of foreign aid that smoothed the way for the strong appreciation of the real exchange rate during the Nyerere regime. It might be interpreted as evidence of a Dutch disease effect of aid. The simultaneous feed-back effects can be given the following interpretation: when income is above its long-run trend the real exchange starts appreciating, and a real appreciation depresses income; when income starts falling the real exchange rate starts depreciating, and a real depreciation leads to increasing income which causes the real exchange rate to appreciate, and so on. Finally, when the real exchange rate was above/below its equilibrium value consumption increased/decreased and investment decreased/increased.

Private consumption is equilibrium error correcting in the fifth relation, which is therefore interpreted as a consumption relation (caveat $i i)$ :

$$
\underset{(-1.69)}{\hat{c}_{t}}=-0.13 \hat{g}_{t}-0.45 \Delta p_{t}
$$

It shows that trend-adjusted consumption has been negatively related to trend-adjusted government expenditure and inflation. Also this can be interpreted as a medium long-run relationship capturing long business cycle behaviour (caveat vi). The results indicate significant substitution effects between 
private consumption and government expenditure in line with previous results. The $\alpha$ coefficients show that investment increased and real income decreased when private consumption exceeded its equilibrium value.

\subsection{A long-run structure for Ghana}

The results for Ghana are reported in Table 5. According to caveat vii cointegration relations 3 and 4 represent long-run steady-state relations, whereas 1, 2 and 5 reflect medium long-run relations.

The first relation is equilibrium correcting to income and aid and, hence, describes simultaneous feedback effects (caveat ii). We have chosen to normalise on income, but could equally well have used aid:

$$
\underset{(-0.41)}{\hat{y}_{t}}=0.44 \widehat{a i d}_{t}
$$

The relation shows that GDP and aid (both corrected for a long-run trend after 1983 as they did not trend before 1983) were positively associated both in the pre-reform period when declining aid led to a decade of no growth and in the reform period when aid started flowing into the country in larger volumes and growth resumed. We interpret the relation as a medium long-run relation describing how real GDP and aid have been associated over political business cycles (caveat vi). The simultaneous feedback of income and aid captures a circle of increasing/decreasing aid generating higher/lower income and higher/lower income resulting in higher/lower aid, and so on. The remaining $\alpha$ coefficients show that the real exchange rate appreciated when income was above its equilibrium value and that investment increased and consumption decreased.

Investment is error-correcting to the second relation which is therefore interpreted as an investment relation (caveat $i$ ):

$$
\underset{(-0.76)}{\widehat{\operatorname{cnv}}_{t}}=0.44 \widehat{\operatorname{aid}}+1.40 \Delta p_{t}-1.9 \hat{g}_{t}
$$

It shows that trend-adjusted investment has been positively associated with trend-adjusted aid and inflation but negatively with trend-adjusted government expenditure after the effect of the former has been controlled for. The negative effect is likely to reflect the pre-reform period of expanding government expenditure at the expense of investment. The relation is interpreted as a medium longrun relation describing behaviour over the medium long-run political cycles (caveat $v i$ ). The $\alpha$ coefficients show that GDP and private consumption decreased when investment was above its long-run trend relative to its determinants.

Altogether it was not possible to estimate a truly long-run Ghanaian investment relation. The finding in Section 3 that investment grew much faster than GDP in the reform period suggests (similar to Tanzania) that investment deserves to be studied in more detail. We therefore recall our initial caveats.

The third relation is equilibrium correcting to the real exchange rate but error increasing in aid and inflation. We interpret it as a relation for the real exchange rate (caveat ii):

$$
\underset{(-0.43)}{\operatorname{rex}_{t}}=-2.70 \operatorname{aid}_{t}+1.20 \operatorname{inv}_{t}-2.44 \Delta p_{t}
$$

The negative coefficient to aid shows that increasing aid has been associated with an appreciating currency (a Dutch disease effect of aid) and increasing investment with a depreciating currency. The negative relationship between the real exchange rate and the inflation rate implies error increasing behaviour over the medium-run (caveat viii). It signifies that in the pre-reform period inflation was increasing while the currency was appreciating and that in the reform period inflation was falling while 


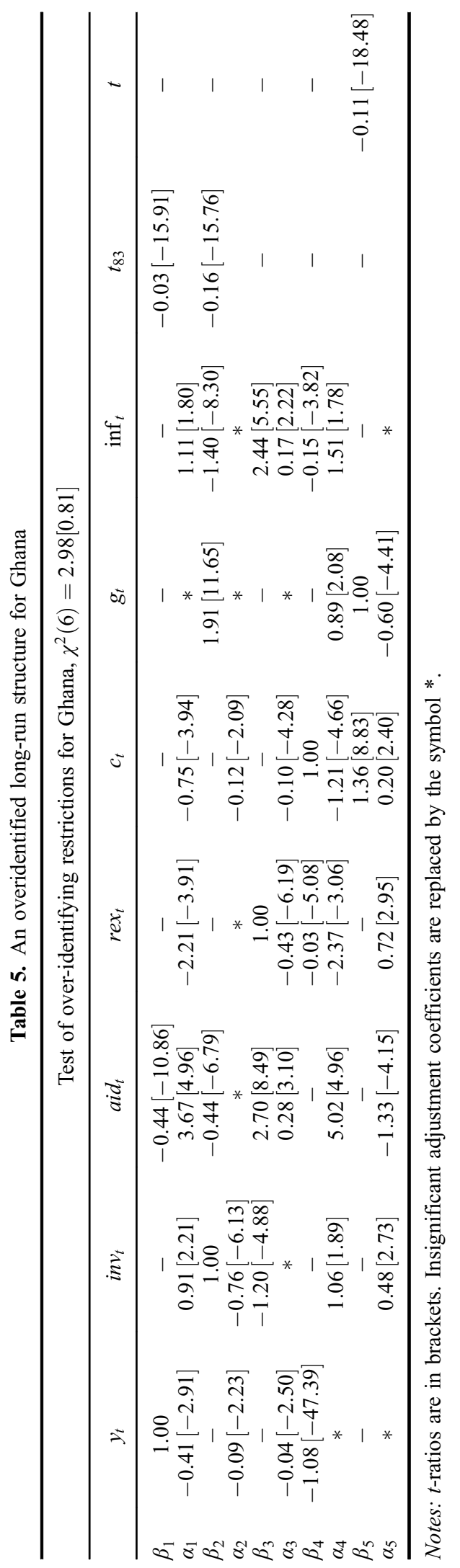


the currency was depreciating. Maintaining an overvalued currency depressed growth in the prereform period, but may have prevented the already very high inflation rates to reach even higher inflationary levels. But deregulating the currency after the strong devaluations in the reform period does not seem to have made nominal exchange rate more equilibrium correcting. Instead, inflation rates kept falling and the currency kept depreciating, a result that seems consistent with imperfect knowledge economics (Frydman \& Goldberg, 2007, 2011).

Furthermore, the $\alpha$ coefficients imply error increasing behaviour in the inflation and aid equations. The former suggests that Ghana might have been very close to very high in the pre-reform period. The latter reflects the Ghanaian vicious/virtous circle: the more the currency appreciated and the more inflation increased in the first period, the less aid was flowing into the country, whereas the more the currency depreciated and the more inflation fell in the reform period, the more aid was flowing into the country. This is another way of saying that donors tended to withdraw their aid when things went badly in the 1970s and did the opposite when the economic performance improved in the 1980s. Finally, the $\alpha$ coefficients of the income and consumption equations show that both variables declined when the real exchange rate was above its equilibrium value (that is had depreciated)

The fourth relation is equilibrium correcting in private consumption and inflation (but not very significantly so) and is error increasing in the real exchange rate. We interpret it as a private consumption relation (caveat $i$ ):

$$
\underset{(-1.21)}{c_{t}}=1.08 y_{t}+0.15 \Delta p_{t}+0.03 r e x_{t}
$$

This relationship suggests that consumption relative to income (roughly proxying the inverse of the savings ratio), is positively related to inflation. When inflation increases so does consumption, that is the savings rate declines. Consumption relative to income is also positively related to the real exchange rate (savings have been low when the real exchange rate has been depreciating). That the real exchange rate is error increasing is further evidence of the complex role the real exchange rate has played in Ghana over this period. The $\alpha$ coefficients show that when consumption was above its steady-state level, investment, government expenditure and aid increased.

Government expenditure is error correcting and private consumption is error increasing in the fifth relation, which is interpreted to be a relation for government expenditure (caveat $i$ ):

$$
\underset{(-0.60)}{\hat{g}_{t}}=-1.36 \hat{c}_{t}
$$

It is interpreted as a medium long-run relation describing behaviour over the political cycle (caveat $v i$ ) and demonstrates (again) a strong substitution effect between government expenditure and consumption when both are corrected for their long-run trend. The error increasing behaviour of private consumption suggests that the latter was increasingly depressed relative to government consumption in the pre-reform period and the other way around in the reform period. The remaining $\alpha$ coefficients show that aid decreased when trend-adjusted government spending was above its steady-state, whereas real exchange rate depreciated and real GDP increased.

\section{Conclusions}

The empirical analysis in this study has, first, revealed both differences and similarities between Tanzania and Ghana. Ultimately, they seem to be associated with the role of the real exchange rate, the inflation rate, and aid for the macroeconomic transmission mechanisms. Both countries experienced a long period of real exchange appreciation in the 1970s and until the mid-1980s. As the real appreciation was not reflected in an equally strong macroeconomic performance, both countries suffered from imbalances in various sectors of the economy. In the end, sizeable devaluations of the domestic currencies were unavoidable: Ghana in 1983 and Tanzania in 1985. 
Tanzania was fortunate to obtain very large inflows of foreign aid in the pre-reform period. This explains why it was possible to maintain an overvalued currency without suffering from economic collapse in spite of apparent economic weaknesses. For Ghana the opposite was the case. Foreign aid stagnated after the Ghanaian government repudiated international debt, and the real appreciation of the currency magnified existing structural weaknesses in the economy. Government expenditure had to be financed by monetary expansion, resulting in very high inflation rates. Declining aid, inflation, and an appreciating currency was a disastrous cocktail for investment. While real GDP and private consumption stagnated in this period, investment followed a negative growth trend, and also real per capita income growth was negative. The empirical finding that investment was negatively associated with government expenditure complements the picture of a military government that was unable to promote real growth.

Due to generous aid inflows, Tanzania experienced positive investment and GDP growth in both the first and the second period. In spite of the aid, the growth rates were not up to expectations, primarily due to the real appreciation of the currency. The results show that while real growth was closely associated with investments it was not a one-to-one relationship. The coefficient to investment $(0.63)$ suggests that some investments were not particularly productive. Similarly as for Ghana, investment in Tanzania suffered from the real appreciation in the first period, but benefitted from devaluations in the post-1985 period and from occasionally quite high inflation rates.

In Ghana, inflation rates soared in the pre-reform period reaching very high levels, suggesting that money expansion went hand in hand with the real appreciation of the currency. That only government expenditure showed some growth over this period is an indication that it was mostly financed by expansions in the money supply. All this changed in 1983 with the adoption of structural reforms including a sizeable devaluation of the currency.

A common feature of the transmission mechanisms is substitution between private consumption and government expenditure, but the effects are opposite of each other in the two countries. In the Ghanaian pre-reform period, government expenditure was allowed to grow at the expense of private consumption. In the reform period, private consumption increased while the government sector declined. In Tanzania, government expenditure generally appears to have been given priority over private consumption. For example, a shock to aid was shown to be negative for private consumption, while positive for government expenditure in Tanzania. The opposite was the case for Ghana.

We turn next to the second and critically important question in the introduction, that is whether the inclusion of real exchange rates (open economy effects) and inflation significantly affects our conclusions regarding the long-run impact of aid on the key macroeconomic variables in the two countries as compared to the findings in JMT14. For Tanzania aid played the dual role of partly financing imports, and partly facilitating a real appreciation. The former promoted growth, while the latter depressed it. This might explain why aid is not very visible in the Tanzanian results. For example, the long-run impact of a shock to aid on the macrovariables was found to be positive albeit only borderline significant. In this sense, aid did not seem to play a strong role as an exogenous driver. This is consistent with the finding that aid was mostly found to be adjusting to the level of real income and the real exchange rate.

For Ghana aid seemed pivotal for real growth in both GDP and investment. The decade of declining aid and essentially no growth in the 1970s and the catch-up after the initiation of the post-1983 structural reforms period, when aid flows started increasing again, are a strong indication of this. For Ghana the long-run impacts of aid were also found to be positive. Altogether, the inclusion of the real exchange rate in combination with an improved specification of the deterministic terms seem to be able to explain the negative Ghana results in JMT14.

As regards to the question whether the effect of the major structural reforms differed for the macroeconomic growth rates in Ghana and Tanzania, the results of Section 5 are clear. They suggest that the growth rates in Tanzania remained essentially unchanged after the initiation of structural reforms in the mid-1980s. In contrast for Ghana the dismal growth rates of the pre-structural reform period were replaced by strong macroeconomic progress. As the main difference between the two countries lies in the large inflows of aid for Tanzania and lack of aid for Ghana in the pre-reform 
period, ultimately the difference in macroeconomic growth seems to be associated with a difference in the generosity of foreign aid. At the same time, the results confirm the importance of maintaining a more balanced real exchange rate for the overall transmission mechanisms of foreign aid. To some extent both Ghana and Tanzania suffered from Dutch disease in the period under study.

Finally, our study has revealed that the macroeconomic mechanisms during the two sub-periods were somewhat different for Tanzania, but radically different for Ghana. The fact that with only 40 annual observations we were not able to split the sample in two more homogeneous periods produced some puzzling results. This was particularly the case with Ghana where the determination of investment and the long-run impact of inflation shocks were empirically difficult to interpret. Also, the results for Ghana provided evidence of several self-reinforcing feedback loops which produced a vicious circle outcome in the first period, but a virtuous one in the second. In this sense the relative abundance of aid flows in Tanzania and the lack of aid in Ghana over the pre-reform period seems to define the difference between a reasonably stable and unstable economic performance.

\section{Acknowledgements}

The authors wish to thank two anonymous referees for very insightful and helpful comments. The usual caveats apply.

\section{Disclosure statement}

No potential conflict of interest was reported by the authors.

\section{Notes}

1. See Nord et al. (2009) and World Bank (2001) for further background.

2. See Ndulu, O'Connel, Bates, Collier, and Soludo (2008) for illuminating background.

3. A CVAR model with nonstationary real variables is econometrically misspecified without including the inflation rate (Kongsted, 2005). Economically, it usually means absence of nominal and real separation.

4. Compared to previous versions of PWT, the government consumption in PWT 7.0 does not include health and education, which are instead part of household consumption.

5. The real effective exchange rate would have been the preferred measure, but it was not possible to calculate it for the full period based on the available data.

6. The ODA data is obtained from the OECD online database. The data on $y_{t}$, inv $v_{t}, c_{t}$ and $g_{t}$ are obtained from the Penn World Table (PWT) online database (Heston, Summers, \& Aten, 2011). The data for the real exchange and inflation rates are taken from the IMF online IFS data base (see also Table A3 in the Appendix). We spotted some data problems in the PWT database. In 2005, government expenditure decreased in Ghana by 55 per cent and increased in Tanzania by 200 per cent. These figures are not credible and inconsistent with the records in the WDI and UN databases. The same seems to be the case with a GDP growth of 14 per cent in 2005 in Tanzania. Such extraordinary changes are likely to be due to changing data definitions and we have corrected these records based on information available in the WDI database for Tanzania and in the UN statistics database for Ghana.

7. That the inflation rate is weakly exogenous may seem surprising, but is likely to be due to the fact that the data are taken from the Penn World Tables. The latter rely on interpolated prices collected roughly every five years by the International Comparison Project.

8. A detailed discussion of Equation (6) can be found in JMT14.

9. For further methodological discussion, see Hendry and Juselius (2000) and Juselius (2006).

10. It should, however, be noted that the data are from Penn World Tables which are interpolated from data collected every five years. This may very well have affected the exogeneity results.

11. It can also be mentioned that Tanzania now became classified as a Case II rather than a Case I country.

\section{References}

Agrawal, N., Ahmed, Z., Mered, M., \& Nord, R. (1993). Structural adjustment, economic performance, and aid dependency in Tanzania (Working Paper No. 1204). Washington, DC: Eastern Africa Department The World Bank and Fiscal Affairs and 
African Departments International Monetary Fund. Retrieved from https://www.imf.org/external/pubs/cat/longres.aspx?sk= 1208.0

Aryeetey, E., Fosu, A., \& Bawumia, M. (2002). Explaining African economic growth performance: The case of Ghana (Growth Working Paper No. 7). Nairobi: African Economic Research Consortium. Retrieved from http://dspace.africaportal.org/jspui/ bitstream/123456789/32135/1/Ghana2.pdf?1 .

Aryeetey, E., Harrigan, J., \& Nisanke, M. (Eds.). (2000). Economic reforms in Ghana: The miracle and mirage. Oxford: James Currey and Woeli.

Aryeetey, E., \& Kanbur, R. (Eds.). (2008). The economy of Ghana: Analytical perspectives on stability, growth \& poverty. Oxford: James Currey and Woeli.

Aryeetey, E., \& Tarp, F. (2000). Structural adjustment and after, which way forward. In E. Aryeetey, H. Jane, \& M. Nisanke (Eds.), Economic reforms in Ghana: The miracle and mirage. Oxford: James Currey and Woeli.

Bigsten, A., \& Danielsson, A. (1999). Is Tanzania an emerging economy? A report for the OECD project "Emerging Africa". Paris: OECD.

Cooksey, B., \& Kelsall, T. (2011). The political economy of the investment climate in Tanzania African power and politics (Research Report No. 01). London: Overseas Development Institute.

Davidson, J. (1998). Structural relations, cointegration and identification: Some simple results and their application. Journal of Econometrics, 87(1), 87-113. doi:10.1016/S0304-4076(98)00007-4

Fosu, A. K., \& Aryeetey, E. (2008). Ghana's post-independence economic growth: 1960-2000. In E. Aryeetey \& R. Kanbur (Eds.), The economy of Ghana: Analytical perspectives on stability, growth \& poverty. Oxford: James Currey and Woeli.

Frydman, R., \& Goldberg, M. (2007). Imperfect knowledge economics: Exchange rates and risk. Princeton, NJ: Princeton University Press.

Frydman, R., \& Goldberg, M. (2011). Beyond mechanical markets: Risk and the role of asset price swings. Princeton, NJ: Princeton University Press.

Gonzalo, J. (1994). Five alternative methods of estimating long-run equilibrium relationships. Journal of Econometrics, 60(1-2), 203-233. doi:10.1016/0304-4076(94)90044-2

Hendry, D. F., \& Juselius, K. (2000). Explaining cointegration analysis. Part 2. The Energy Journal, 22(1), 1-52.

Heston, A., Summers, R., \& Aten, B. (2011). Penn world table version 7.0. Center for International Comparisons of Production, Income and Prices at the University of Pennsylvania.

Hoover, K. (2012). Pragmatism, perspectival realism, and econometrics. In A. Lehtinen, J. Kuorikoski, \& P. Ylikoski (Eds.), Economics for real: Uskali Mäki and the place of truth in economics. London: Routledge.

Husain, I., \& Faruqee, R. (Eds.). (1994). Adjustment in Africa: Lesson from a country case study. Washington, DC: World Bank.

Johansen, S. (1995). Identifying restrictions of linear equations. With applications to simultaneous equations and cointegration. Journal of Econometrics, 69(1), 111-132. doi:10.1016/0304-4076(94)01664-L

Johansen, S. (1996). Likelihood-based inference in cointegrated vector autoregressive models. Oxford: Oxford University Press.

Johansen, S. (2002). A small sample correction for the test of cointegration rank in the vector autoregressive model. Econometrica, 70, 1929-1961. doi:10.1111/1468-0262.00358

Johansen, S. (2012). The analysis of nonstationary time series using regression, correlation and cointegration. Contemporary Economics, 6, 40-57. doi:10.5709/ce.1897-9254.39

Johansen, S., \& Juselius, K. (1994). Identification of the long-run and the short-run structure an application to the ISLM model. Journal of Econometrics, 63, 7-36. doi:10.1016/0304-4076(93)01559-5

Juselius, K. (2006). The cointegrated VAR model. Methodology and applications. Oxford: Oxford University Press.

Juselius, K., Møller, N. F., \& Tarp, F. (2014). The long-run impact of foreign aid in 36 African countries: Insights from multivariate time series analysis. Oxford Bulletin of Economics and Statistics, 76(2), 153-184. doi:10.1111/obes.2014.76. issue-2

Kongsted, H. C. (2005). Testing the nominal-to-real transformation. Journal of Econometrics, 124(2), 205-225. doi:10.1016/j. jeconom.2004.02.016

Leechor, C. (1994). Ghana: Frontrunner in adjustment. In I. Husain \& R. Faruqee (Eds.), Adjustment in Africa: Lesson from country case study. Washington, DC: World Bank.

Ndulu, B., O’Connel, S. A., Bates, R. H., Collier, P., \& Soludo, C. C. (Eds.). (2008). The political economy of economic growth in Africa, 1960-2000. Cambridge, UK: Cambridge University Press.

Nielsen, H. B. (2008). Influential observations in cointegrated VAR models: Danish money demand 1973-2003. The Econometrics Journal, 11(1), 39-57. doi:10.1111/j.1368-423X.2007.00226.x

Nord, R., Sobolev, Y., Dunn, D., Hajdenberg, A., Hobdari, N., Maiad, S., \& Roydet, S. (2009). Tanzania: The story of an African transition. Washington, DC: International Monetary Fund.

Potts, D. (2005). Policy reform and the economic development of Tanzania (Research Paper No.14). Bradford: Bradford Centre for International Development.

Rotarou, E., \& Ueta, K. (2009). Foreign aid and economic development: Tanzania's experience with ODA. The Kyoto Economic Review, 78(2), 157-189.

Tsikata, Y. M. (2001). Owning economic reforms. A comparative study of Ghana and Tanzania (Discussion Paper No. 53). Helsinki: United Nations University WIDER.

Van Arkadie, B. (1995). Economic strategy and structural adjustment in Tanzania. (Private Sector Development Department Occasional paper No. 18). Washington, DC: World Bank. 
Wobst, P. (2001). Structural adjustment and intersectoral shifts in Tanzania: A computable general equilibrium analysis (Research Report No. 117). Washington, DC: International Food Policy Research Institute.

World Bank. (2001). Tanzania at the turn of the century: From reforms to sustained growth and poverty reduction. World Bank Country Study. Washington, DC : World Bank. Retrieved from http://documents.worldbank.org/curated/en/ 727001468778229551/Tanzania-at-the-turn-of-the-century-from-reforms-to-sustained-growth-and-poverty-reduction

\section{Appendix}

Table A1. Misspecification tests

\begin{tabular}{|c|c|c|c|c|}
\hline \multirow[b]{2}{*}{ Bivariate tests } & \multicolumn{2}{|c|}{ Ghana } & \multicolumn{2}{|c|}{ Tanzania } \\
\hline & Normality & $\mathrm{ARCH}(2)$ & Normality & ARCH(2) \\
\hline$\Delta y_{t}$ & $7.85[0.02]$ & $0.69[0.71]$ & $3.70[0.16]$ & $0.11[0.95]$ \\
\hline$\Delta i n v_{t}$ & $0.01[1.00]$ & $0.87[0.65]$ & $6.37[0.04]$ & $0.50[0.78]$ \\
\hline$\Delta a i d_{t}$ & $0.50[0.78]$ & $6.16[0.05]$ & $1.08[0.58]$ & $3.96[0.14]$ \\
\hline$\Delta r e x_{t}$ & $0.70[0.70]$ & $0.99[0.61]$ & $1.67[0.43]$ & $3.09[0.21]$ \\
\hline$\Delta c_{t}$ & $0.59[0.74]$ & $2.58[0.28]$ & $1.67[0.43]$ & $1.97[0.37]$ \\
\hline$\Delta g_{t}$ & $1.78[0.41]$ & $8.04[0.02]$ & $3.81[0.15]$ & $0.01[1.00]$ \\
\hline$\Delta \inf _{t}$ & $12.99[0.00]$ & $8.04[0.02]$ & $6.92[0.03]$ & $11.94[0.00]$ \\
\hline \multicolumn{5}{|l|}{ Multivariate tests } \\
\hline Autocorr. LM(1): & \multicolumn{2}{|c|}{$\chi^{2}(49)=63.20[0.08]$} & \multicolumn{2}{|c|}{$\chi^{2}(49)=72.18[0.02]$} \\
\hline $\operatorname{LM}(2)$ & \multicolumn{2}{|c|}{$\chi^{2}(49)=38.65[0.86]$} & \multicolumn{2}{|c|}{$\chi^{2}(49)=44.49[0.66]$} \\
\hline ARCH LM(1) & \multicolumn{2}{|c|}{$\chi^{2}(784)=825.36[0.15]$} & \multicolumn{2}{|c|}{$\chi^{2}(784)=817.02[0.20]$} \\
\hline Normality & \multicolumn{2}{|c|}{$\chi^{2}(14)=20.46[0.12]$} & \multicolumn{2}{|c|}{$\chi^{2}(14)=24.47[0.04]$} \\
\hline
\end{tabular}




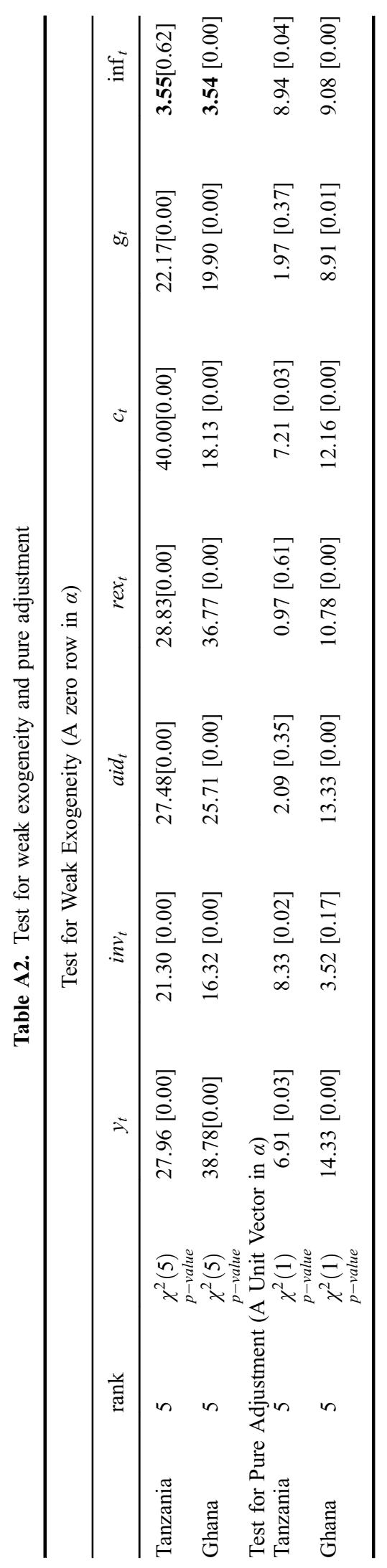


Table A3. Variable definition and descriptions

\begin{tabular}{|c|c|c|}
\hline Variable & Description & Source \\
\hline$y_{t}$ & $\begin{array}{l}\text { Logarithm of PPP converted GDP at } 2005 \text { constant prices. PWT } 7.0 \text { reports the } \\
\text { PPP converted GDP per capita (Laspeyres) at } 2005 \text { constant prices (rgdpl). For } \\
\text { the purpose of our analysis we multiplied GDP per capita by total population and } \\
\text { took its logarismic form. }\end{array}$ & PWT $7.0^{\mathrm{a}}$ \\
\hline$c_{t}$ & $\begin{array}{l}\text { Logarithmic of PPP converted actual household consumption at } 2005 \text { constant } \\
\text { price. }\end{array}$ & PWT 7.0 \\
\hline$g_{t}$ & $\begin{array}{l}\text { Logarithm of PPP converted Government Consumption at } 2005 \text { constant prices. } \\
\text { Unlike previous PWT, the government consumption in PWT } 7.0 \text { does not include } \\
\text { health and education because they are instead added to actual household } \\
\text { consumption. }\end{array}$ & PWT 7.0 \\
\hline int $_{t}$ & $\begin{array}{l}\text { Logarithm of PPP converted domestic investment (gross capital formation) at } 2005 \\
\text { constant prices. }\end{array}$ & PWT 7.0 \\
\hline $\operatorname{rex}_{t}$ & $\begin{array}{l}\text { The real exchange rate is defined as } r e x_{t}=\log \left(s_{t} \times p_{t}^{*} / p_{t}\right) \text {. Where } s_{t} \text { is the } \\
\text { domestic currency versus the dollar rate and } p_{t}^{*} / p_{t} \text { measures the relative } \\
\text { consumer prices between USA and the domestic country. }\end{array}$ & IMF IFS \\
\hline$\Delta p_{t}$ & Inflation rate is obtained by taking first difference of consumer price index. & IMF IFS \\
\hline
\end{tabular}

